Article

\title{
Processing of Alnico Magnets by Additive Manufacturing
}

\author{
Emma White ${ }^{1, * \mathbb{C}}$, Emily Rinko ${ }^{2}$, Timothy Prost ${ }^{1}{ }^{\mathbb{D}}$, Timothy Horn ${ }^{3,4}$, Christopher Ledford $^{4}$, \\ Christopher Rock ${ }^{4}$ and Iver Anderson ${ }^{1,2}$ \\ 1 Ames Laboratory of USDOE, Ames, IA 50011, USA; tprost@ameslab.gov (T.P.); andersoi@ameslab.gov (I.A.) \\ 2 Department of Materials Science and Engineering, Iowa State University, Ames, IA 50011, USA; \\ earinko@iastate.edu \\ 3 Department of Mechanical and Aerospace Engineering, Center for Additive Manufacturing and Logistics, \\ North Carolina State University, Raleigh, NC 27695, USA; tjhorn@ncsu.edu \\ 4 Edward P. Fitts Department of Industrial and Systems Engineering, Center for Additive Manufacturing and \\ Logistics, North Carolina State University, Raleigh, NC 27695, USA; jcledfo2@ncsu.edu (C.L.); \\ cdrock@ncsu.edu (C.R.) \\ * Correspondence: ewhite@ameslab.gov
}

Received: 16 August 2019; Accepted: 24 October 2019; Published: 12 November 2019

Featured Application: For potential application in electric drive motors and advanced high temperature magnet technologies.

\begin{abstract}
Permanent magnets without rare earth (RE) elements, such as alnico, will improve supply stability and potentially decrease permanent magnet cost, especially for traction drive motors and other increased temperature applications. Commercial alnico magnets with the highest energy product are produced by directional solidification (DS) to achieve a $<001>$ columnar grain orientation followed by significant final machining, adding to the high cost. Additive manufacturing (AM) is an effective method to process near net-shape parts with minimal final machining of complex geometries. $\mathrm{AM}$ also, has potential for texture/grain orientation control and compositionally graded structures. This report describes fabrication of alnico magnets by AM using both laser engineered net shaping (LENS)/directed energy deposition (DED) and electron beam melting powder bed fusion (EBM/PBF). High pressure gas atomized (HPGA) pre-alloyed alnico powders, with high purity and sphericity, were built into cylindrical and rectangular samples, followed by magnetic annealing (MA) and a full heat treatment (FHT). The magnetic properties of these AM processed specimens were different from their cast and sintered counterparts of the same composition and show a great sensitivity to heat treatment. The AM process parameters used in this developmental study did not yet result in any preferred texture within the alnico AM builds. These findings demonstrate feasibility for near net-shape processing of alnico permanent magnets for use in next generation traction drive motors and other applications requiring increased operating temperatures and/or complex engineered part geometries, especially with further AM process development for texture control.
\end{abstract}

Keywords: additive manufacturing; permanent magnets; alnico

\section{Introduction}

Research into viable alternative magnet solutions is motivated by price fluctuations and supply uncertainty of rare earth oxides and metals (e.g., Dy, Nd, and Pr), which are key components in high energy product $\left(\mathrm{BH}_{\max }\right)$ rare earth $(\mathrm{RE})$ permanent magnets $[1,2]$. Alternative permanent magnets, such as alnico, with significant improvement, provide the prospect of reduced supply instability and 
drastically decreased manufacturing costs for certain higher temperature applications such as traction drive motors [1,2]. A greater variety of magnets for high temperature conditions $\left(\sim 200^{\circ} \mathrm{C}\right)$ and medium energy product applications could rejuvenate RE-free magnet production and enhance production stability through removing reliance on foreign products. Alnico is a promising near-term non-RE permanent magnet because of its impressive saturation magnetization and exceptional thermal stability, featuring nearly flat magnetic property temperature dependence up to $400{ }^{\circ} \mathrm{C}$ [1]. Additionally, alnico presents potential for high remanence and excellent mechanical properties if powder processing improvements are successful. Next generation motor designs for automotive applications presently exist that utilize alnico magnets considering projected elevated temperature energy products [1].

Developed in the 1930s, this class of permanent magnets has intricate compositions, complex processing and byzantine heat treatments that were optimized empirically for roughly the next four decades [3-10]. Due to a spinodal decomposition of the high temperature partially ordered $\operatorname{Im} \overline{3} \mathrm{~m}$ phase (B2-type) in alnico, a magnetic Fe-Co-rich $\left(\alpha_{1}, \mathrm{Pm} \overline{3} \mathrm{~m}\right.$ crystal structure) phase and a non-magnetic Al-Ni-rich $\left(\alpha_{2}, \mathrm{~L} 2_{1}\right.$ or $\mathrm{Fm} \overline{3} \mathrm{~m}$ crystal structure) matrix phase form during cooling [11]. Although providing the permanent magnet properties to alnico, this spinodal transformation significantly increases the processing complexity of this alloy $[11,12]$. Shape anisotropy is generally considered to be the overarching mechanism for coercivity in alnico magnets, achieved after thermal annealing in a magnetic field, i.e., magnetic annealing (MA), which results in a spinodal nanoscale structure with the $\alpha_{1}$ elongated along the applied field direction $[11,12]$. To fully realize the maximum coercivity for a given MA treatment, alnico magnets are subject commonly to extended (1-20 h duration) low temperature $\left(550-650^{\circ} \mathrm{C}\right.$ ) annealing ("draw" cycles) and the combination of the MA and drawing cycles is termed full heat treatment (FHT). Recent in-depth studies of different alnico compositions have shown that very minor chemistry, processing and heat treatment changes produce distinctly different micro- and nanoscale structures, resulting in differences in remanence and coercivity, in addition to other magnetic properties [11,13].

To produce alnico 9 magnets with the highest energy product $\left(\mathrm{BH}_{\max } \sim 10.5 \mathrm{MGOe}\right)$, directionally solidified casting is required to align grains primarily along the $<001>$ direction with considerable cost, time, and complexity $[7,11,14]$. Significant machining of these castings into final shapes removes the un-textured exterior surfaces to yield the highest energy product, but with only a coercivity of $1.5 \mathrm{kOe}$. This final machining and additional defects within these castings lead to embrittlement and breakage that requires reprocessing and large amounts of scrap material, increasing costs and material process waste [14]. Of the commercially available alnico compositions, crystallographically isotropic alnico $8 \mathrm{H}$ has the highest coercivity $(2.02 \mathrm{kOe})$, but a relatively low energy product of 7.0 MGOe when compared to its RE alternatives [11]. However, the experimentally measured magnetic properties of all alnico compositions are estimated to be less than half the calculated energy product theoretically possible by refining and controlling the nanostructure and by composition and processing optimization, guided by modern techniques [11]. Thus, enhanced alnico permanent magnets with an energy product of 20 MGOe could be achieved that would match, or outperform, both Dy-enriched Nd-Fe-B and Sm-Co-based permanent magnets operating at $150-200{ }^{\circ} \mathrm{C}$ [11].

Additive manufacturing (AM) has great potential to be applied in the permanent magnet industry for near-net shape complex parts, system integration, functionally graded magnetic materials and complicated magnetic field generation [15-18]. In most AM fusion processes, parts are built up one layer at a time as new material is melted and solidified onto the layer below using a laser or electron beam as a localized heat source. AM eliminates expensive dies and molds, and reduces material waste drastically by requiring only minimal machining to final shape [15]. AM broadens the available processing space and empowers geometries not possible by traditional manufacturing, providing exciting possibilities for grain texture control for tailored isotropic or anisotropic properties $[15,19]$. In particular, alnico magnetic properties can be increased if a textured, columnar grain microstructure results, thus motivating exploration of an AM processing route for alnico magnet fabrication [10,19]. $\mathrm{EBM} / \mathrm{PBF}$ of alnico has not been performed to date due to concerns about electron beam created 
magnetic fluxes within the AM build chamber and potential for interactions with the magnetic AM feedstock powders. Tight control of the localized heat input and pre-heat temperature relative to the Curie temperature of the material is required in order to be able to AM process magnetic materials. AM processing of Nd-Fe-B has been attempted in Li's and Paranthaman's studies showing the inability to obtain non-bonded magnets of these RE magnet alloys with good properties $[17,18]$.

This work describes AM processing of alnico magnets made from high-pressure gas atomized (HPGA) pre-alloyed powders $[16,20,21]$ of custom compositions using both laser melted directed energy deposition (DED) and electron beam melted powder bed fusion (EBM/PBF) AM systems. Custom compositions include a full-Co alnico designed to increase coercivity and a Co-lean alnico designed to also increase coercivity, but with reduced Co content, an element that is likely to see a supply strain in the future due to its use in batteries [22-24]. The resulting alnico samples were characterized with scanning electron microscopy (SEM), electron backscatter diffraction (EBSD), and closed loop hysteresigraph measurements. The buildability of alnico and resulting magnetic properties can help establish the case for making alnico magnet components by AM for next generation motors and other high temperature, functionally graded or complex engineered part geometry applications.

\section{Materials and Methods}

\subsection{DED Process}

DED alnico alloy feedstock powders were produced via HPGA by Ames Laboratory's (Ames) Powder Synthesis and Development Facility (PSDF). These powders were screen classified using ASTM screen sizes and an Elcan Hi-Sifter to $45-106 \mu \mathrm{m}$ for the DED experiments. Preliminary DED builds using an Optomec MR-7 system were described in a previous paper [16] and additional processing space was systematically explored in this work as described in Tables 1 and 2 to promote heat extraction along the vertical axis of the builds (i.e., draw versus raster). For the samples utilizing the melt pool sensor (MPS) the laser power was varied by the MPS to maintain a constant size of a melt pool with $100 \mathrm{~W}$ for the set power level, $200 \mathrm{~W}$ for the upper limit, $70 \mathrm{~W}$ for the lower limit, and actual variation during the build between 130 and $160 \mathrm{~W}$. Goal cylindrical geometries were $\geq 3 \mathrm{~mm}$ diameter by $25 \mathrm{~mm}$ tall.

Table 1. DED processing parameters for full-Co alnico build samples.

\begin{tabular}{ccccc}
\hline Sample ID & Powder Feed (rpm) & Print Method & Speed (Steps/s) & Power $(\mathbf{W})$ \\
\hline A & 12 & Draw & 1200 & 120 \\
B & 16 & Draw & 2000 & 160 \\
C & 16 & Draw & 3000 & 160 \\
D & 16 & Draw & 3000 & 120 \\
E & 8 & Draw & 800 & 90 \\
F & 16 & Draw & 4000 & 160 \\
G & 16 & Draw & 3000 & $100^{*}$ \\
H & 12 & Draw & 3000 & $100^{*}$ \\
I & 9 & Draw & 3000 & $100 *$ \\
J & 9 & Draw & 2000 & $100^{*}$ \\
K & 9 & Draw & 1500 & $100 *$ \\
\hline
\end{tabular}

* refers to the melt pool sensor (MPS) control. 
Table 2. DED processing parameters for Co-lean alnico build samples.

\begin{tabular}{ccccc}
\hline SAMPLE ID & Powder Feed (rpm) & Print Method & Speed (Steps/s) & Power (W) \\
\hline 1 & 8.0 & Draw & 1600 & 100 \\
2 & 8.0 & Draw & 1600 & 100 \\
3 & 8.0 & Draw & 1600 & 100 \\
4 & 8.0 & Draw & 1600 & 100 \\
5 & 8.0 & Draw & 1600 & 100 \\
6 & 8.0 & Draw & 1600 & 100 \\
7 & 8.0 & Draw & 1600 & 100 \\
8 & 8.0 & Draw & 1600 & 100 \\
\hline
\end{tabular}

\subsection{EBM/PBF Process}

EBM/PBF feedstock alnico alloy powder [25] from the Ames Co-lean composition was produced via inert gas atomization commercially by Carpenter Powder Products (CPP). The powder was screen classified using ASTM screen sizes and an Elcan Hi-Sifter to the 45-106 $\mu \mathrm{m}$ size range for the electron beam AM experiments. A total of five exploratory EBM/PBF experiments/runs were carried out on a customized Arcam A2 electron beam melting system to ascertain the feasibility of alnico processing and to gauge the magnitude of beam-powder interactions. The experimental setup is shown in Figure 1. The build substrate was 304 stainless steel for the first two runs and Ti-6Al-4V for the remaining runs, measuring $90 \mathrm{~mm}$ in diameter and $50 \mathrm{~mm}$ thick (Figure 1A, inset). On each of the first four substrates, four samples with cross sections measuring $20 \mathrm{~mm} \times 20 \mathrm{~mm}$ were produced, and on the last run a single specimen with a cross section measuring $35 \mathrm{~mm} \times 35 \mathrm{~mm}$ was produced. The height of each build sample varied, and was determined by the relative success or failure of a given parameter set.
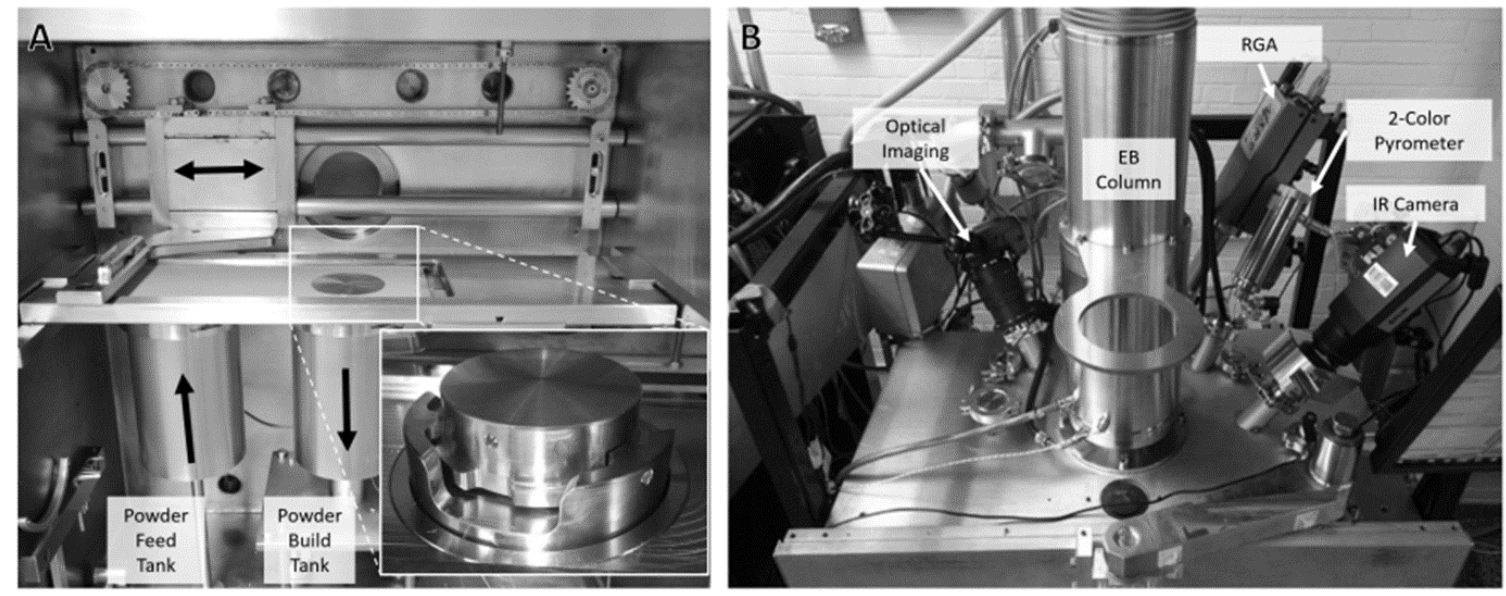

Figure 1. Photos of (A) the EBM/PBF small build volume chamber internal to the system, and (B) an external system view with the electron beam column and available monitoring sensors on top of the build chamber.

During each run, the temperature at the bottom of the build substrate was measured with a thermocouple, and the temperature of powder bed surface was monitored with a 2-color pyrometer (Fluke Process Endurance, E1RL-F1-V-0-0, Fluke, Everett, WA, USA) through a sapphire viewport built into the vacuum chamber (Guild Optics, Amherst, NH, USA) and a spot size of $1 \mathrm{~cm}$ centered between the four melt samples. Melt monitoring was observed using an IR thermal imaging camera (FLIR A655sc, FLIR, Wilson, OR, USA) through a germanium port at $25 \mathrm{~Hz}$.

The limited quantity of powder feedstock necessitated an iterative, 'greedy' parameter development strategy, wherein the results and lessons learned from one iteration were leveraged into the next, and so on, with the primary objective of producing samples of high density and the secondary objective of producing the desired epitaxial grain growth, and solidification conditions. EBM/PBF 
operation and process parameters have been described in detail elsewhere [15]. The Arcam EBM/PBF layer preheating and melting parameters for each run are shown in Tables 3 and 4, respectively. The standard, commercially available parameter set for Ti-6Al-4V was used as a base parameter set for these experiments (Arcam Build Control Software V3.2, SP2), and the values shown are only those that were modified from the standard settings. Note that in the last run, each layer was melted twice. The second melting step incorporated a heavily defocused beam, as it was found that this improved the flatness of each layer and consequently the spreading of the subsequent layer. For all trials the layer thickness was $70 \mu \mathrm{m}$.

Table 3. Preheating parameters used in each EBM/PBF run.

\begin{tabular}{cccccc}
\hline Parameter & Run \#1 & Run \#2 & Run \#3 & Run \#4 & Run \#5 \\
\hline Preheat: Square (mm) & 60 & 60 & 90 & 90 & 90 \\
Preheat 1: Line Order & 15 & 15 & 10 & 10 & 10 \\
Preheat 1: Line Offset (mm) & 1.5 & 1.5 & 0.6 & 0.6 & 0.6 \\
Preheat 1: Hatch Depth (mm) & 0.1 & 0.1 & 0.1 & 0.1 & 0.1 \\
Preheat 1: Max Beam Current (mA) & 24 & 10 & 16 & 17 & 18 \\
Preheat 1: Min Beam Current (mA) & 0.1 & 8 & 5 & 5 & 5 \\
Preheat 1: Beam Speed (m/s) & 8 & 5 & 8 & 7.5 & 7.5 \\
Preheat 1: Number of Repetitions & 40 & 40 & 15 & 16 & 19 \\
Preheat 1: Max Number of Repetitions & 40 & 40 & 20 & 22 & 21 \\
Preheat 1: Average Current (mA) & 2 & 2 & 10 & 14 & 14 \\
\hline
\end{tabular}

Table 4. Melting parameters used in each EBM/PBF run.

\begin{tabular}{ccccccc}
\hline Parameter & Run \#1 & Run \#2 & Run \#3 & Run \#4 & Run \#5 & Run \#5 Pass 2 \\
\hline Melt: Power Analysis $\left({ }^{\circ} \mathrm{C}\right)$ & 850 & 1000 & 1200 & 1300 & 1300 & 1300 \\
Melt: Beam Speed (mm/s) & 200 & 800 & 600 & 600 & 700 & 200 \\
Melt: Current (mA) & 3.5 & 7 & 15 & 9 & 9 & 13 \\
Melt: Max Current (mA) & 3.5 & 7 & 15 & 9 & 9 & 14 \\
Melt: Focus Offset (mA) & 3 & 5 & 7 & 7 & 7 & 25 \\
Melt: Speed Function & 10 & 10 & 30 & 25 & 20 & 6 \\
Melt: Line Offset (mm) & 0.1 & 0.2 & 0.2 & 0.2 & 0.3 & 0.3 \\
\hline
\end{tabular}

\subsection{Magnetic Property Measurement}

Samples were cut from EBM/PBF Run \#5 in the transverse direction as shown in Figure 2 to sample the volume of build which was not affected by the build plate proximity. The remainder of the material was sectioned and polished for inspection. Samples were made in the transverse direction at the top surface above the cylinders, mid cylinder, and below the cylinder; further, a sample was prepared containing a region of interest (ROI) as identified in Figure 2, and includes a test cylinder left behind during the extraction process. This region includes material which was slated for removal but was damaged in the electrical discharge machining (EDM) process. (The dark regions in Figure 16 forming a "fish-hook" shape is where the EDM wire had removed material before the wire broke. This allowed for investigation of the as-built microstructure within one of the cylinders. This particular section was subjected to a SOQ in order to analyze the post-SOQ microstructure.) 

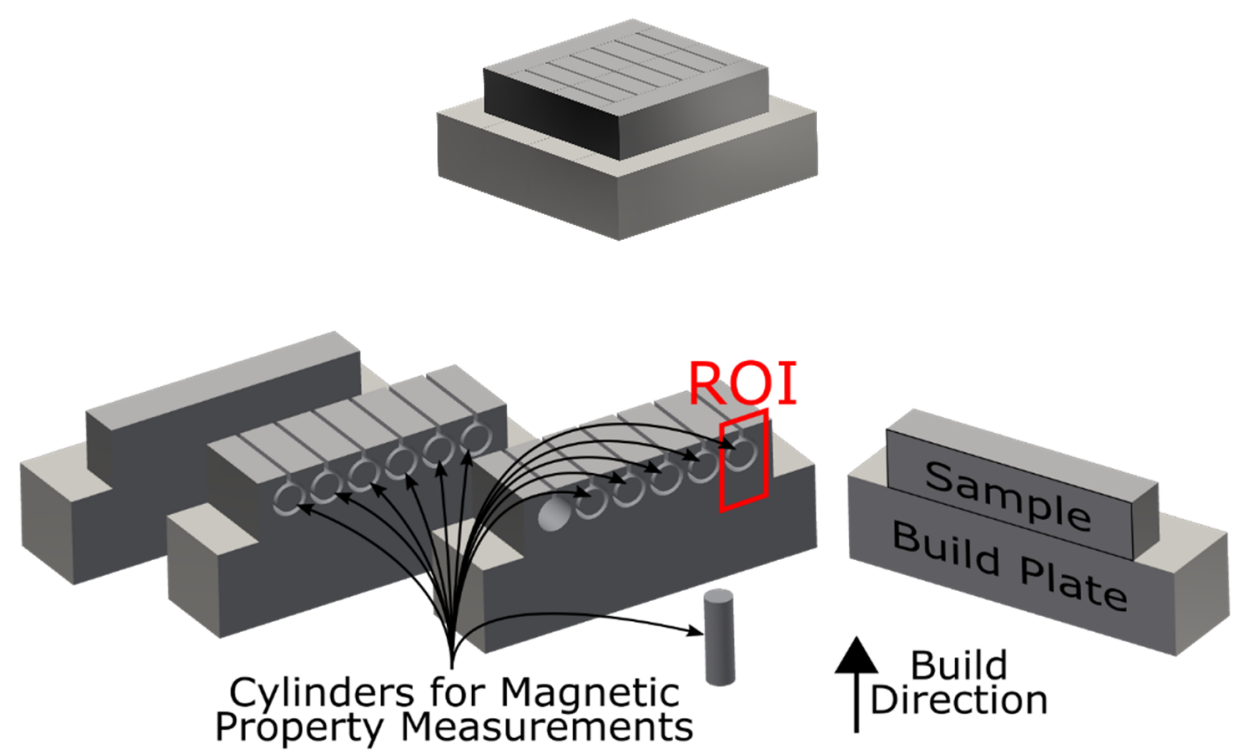

Figure 2. Sectioning and sampling schematic for EBM/PBF Run \#5 sample. The two middle sections are $10 \mathrm{~mm}$ wide and intended for magnetic sample extraction. Region of interest (ROI) for Figure 16 identified in red. Build direction identified as up, all other directions referred to as transverse.

The AM samples from DED and EBM/PBF run \#5 were machined to $\sim 8 \mathrm{~mm}$ tall by $3 \mathrm{~mm}$ diameter cylinders for magnetic property measurements. When possible, multiple cylinders were extracted from along the length of the DED samples. Samples were visually examined for quality (i.e., not chipped from machining). Cylinders of the highest integrity and dimensional quality were selected for the MA and FHT to measure magnetic properties. In preparation for MA, the cylinders were solutionized at $1210{ }^{\circ} \mathrm{C}$ or $1215{ }^{\circ} \mathrm{C}$ for $30 \mathrm{~min}$ and oil quenched (SOQ) in order to obtain a partially ordered $\mathrm{B} 2$ single phase ( $\operatorname{Im} \overline{3} \mathrm{~m}$ crystal structure) uniformly throughout the cylinder. Selected material pieces left over from the cylinder machining process were also subjected to the same SOQ process to verify any microstructural changes occurring. SOQ is a common and necessary practice in alnico magnet fabrication in order to "reset" the nanostructure to a single phase (B2) before developing the $\alpha_{1}$ $+\alpha_{2}$ nanostructure in a spinodal transformation on cooling or heating [3,11,26-28]. The cylinders were cleaned with ethanol and vacuum sealed in a quartz tube (45 torr). To assure a clean and dry environment within the quartz tube, a vacuum of 60 torr or less was reached, then back-filled with argon (repeated three times). The tube was placed in a custom resistance furnace that can be inserted into the air gap of an electromagnet capable of $1.5 \mathrm{~T}$. The MA process was completed at $830-870{ }^{\circ} \mathrm{C}$ for 1-8 min with an applied field of $1 \mathrm{~T}$. Following the MA process an additional heat treatment was completed $\left(650^{\circ} \mathrm{C}\right.$ for $5 \mathrm{~h}, 580^{\circ} \mathrm{C}$ for $15 \mathrm{~h}$, in air, no applied magnetic field) to bring the alnico magnets to their FHT condition. As for the DED samples, all samples (except for one sample, C-2) underwent an $835^{\circ} \mathrm{C}$ MA for 8 min due to the limited number of samples produced. The same FHT parameters used for the EBM/PBF samples were utilized for all DED samples to examine the influence of the DED processing parameters on magnetic properties. Magnetic properties were determined using a closed-loop hysteresigraph (Laboratorio Elettrofisico AMH-500) with a maximum applied field of $20 \mathrm{kOe}$. The density of each cylinder was determined via the geometrical density method.

\subsection{Material Characterization}

Compositions were collected via inductively coupled plasma-mass spectrometry (ICP-MS) from an external vendor. The chemistry of the solid EBM/PBF run \#5 sample was measured with wavelength dispersive X-ray florescence (XRF) (Thermo Scientific ARL PERFORM'X XRF 4200) and energy dispersive X-ray spectroscopy (EDS). Microstructural analysis was performed via SEM (Thermo Scientific Teneo LoVac) and EDS and EBSD were performed with the attached systems (Oxford Max 
80 and Nordlys Nano, respectively). EBSD information was correlated with the microstructural information and figures were compiled wherein orientation of individual pixels is color coded and overlaid on top of the micrographs. Further, pole figures (PF) and inverse pole figures (IPF) were created to quantify the degree of texturing, or lack thereof, within each region of interest.

\section{Results}

The results section is separated into three sections focused on characterization of the following:

- Powder samples used for the AM studies;

- DED built samples, and;

- $\mathrm{EBM} / \mathrm{PBF}$ built samples.

\subsection{Powder Characterization}

\subsubsection{Chemistry}

The powder compositions used in this study as determined by ICP-MS are included in Table 5, as compared with standard commercially available alnico $8 \mathrm{H}$ and alnico 9 compositions.

Table 5. Powder compositions of the AM feedstock materials compared with reported commercial alnico $8 \mathrm{H}$ and alnico 9 compositions.

\begin{tabular}{ccccccccc}
\hline at. $\%$ & Fe & $\mathbf{A l}$ & $\mathbf{N i}$ & $\mathbf{C o}$ & $\mathbf{C u}$ & $\mathbf{T i}$ & $\mathbf{N b}$ & AM System \\
\hline Full Co & 26.05 & 14.63 & 13.21 & 33.99 & 3.15 & 8.68 & 0.28 & DED \\
Co-lean Ames & 30.28 & 14.52 & 14.77 & 28.98 & 2.60 & 8.33 & 0.51 & DED \\
Co-lean CCP & 30.64 & 14.31 & 14.54 & 29.05 & 2.58 & 8.55 & 0.33 & EBM/PBF \\
alnico 8H & 28.50 & 13.96 & 11.75 & 36.09 & 2.50 & 7.20 & 0 & NA \\
alnico 9 & 33.83 & 13.81 & 11.88 & 37.97 & 2.68 & 5.56 & 0.29 & NA \\
\hline
\end{tabular}

\subsubsection{Morphology}

The gas atomized powders had a generally spherical morphology with some small satellite features as shown in Figures 3 and 4 below. Typically, the commercial vendor powders visually showed a slightly higher satellite content than the Ames produced powders and automated size distribution analysis results (not shown) revealed the Ames powders had a higher fine powder proportion present in the $45-106 \mu \mathrm{m}$ size cut.

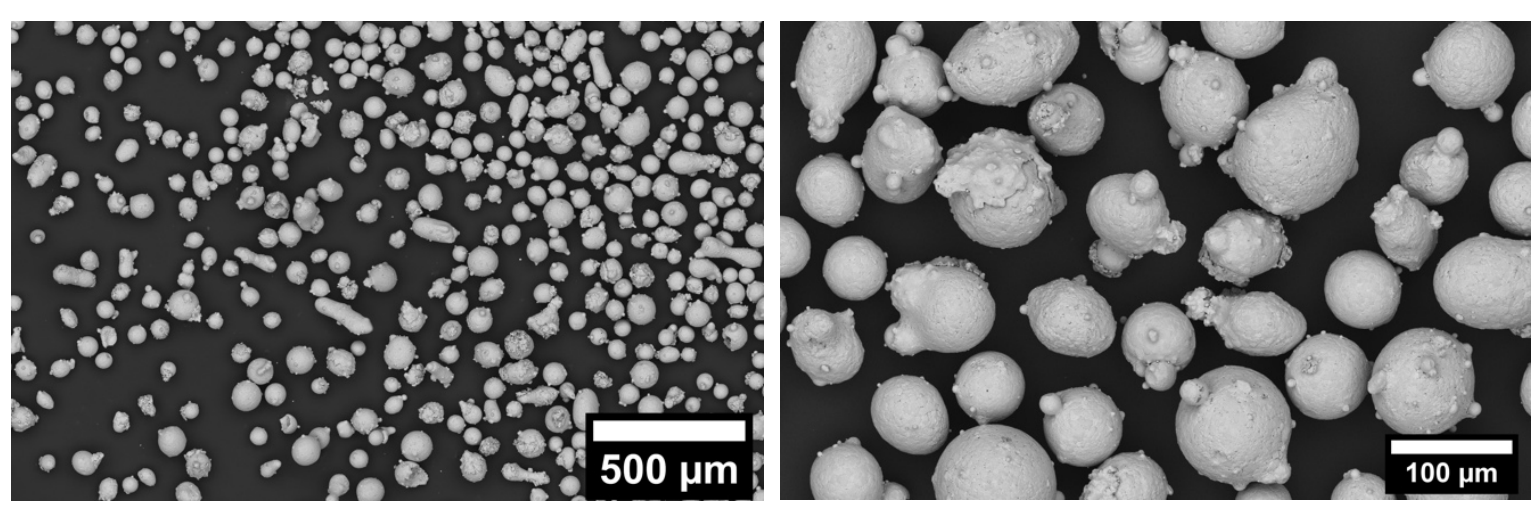

Figure 3. SEM micrographs of alnico (Co-lean) powder prepared by CPP, 45-106 $\mu \mathrm{m}$ cut used for EBM/PBF samples. 

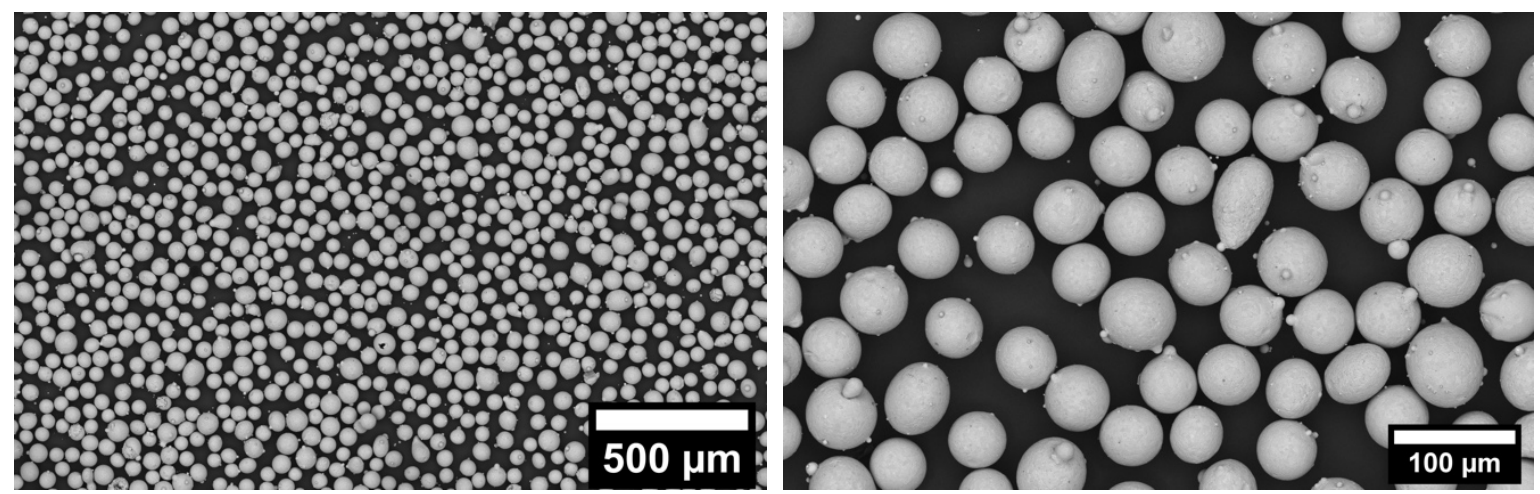

Figure 4. SEM micrographs of alnico (full-Co) powder produced by Ames, 45-75 $\mu \mathrm{m}$ cut used for DED sample. Co-lean powder produced by Ames for DED was of similar quality.

\subsection{DED Additive Manufacturing}

\subsubsection{Process Optimization}

According to the previously listed full-Co and Co-lean DED sample parameters optical images of the samples in the as-built condition are included in Figures 5 and 6, showing variation in sample quality based on the processing parameters. Qualitatively, the best full-Co samples appeared to be B, C and $\mathrm{F}$ for sample consistency and length, corresponding to the highest power level of $160 \mathrm{~W}$. The best Co-lean samples qualitatively appeared to be 1 through 4 .
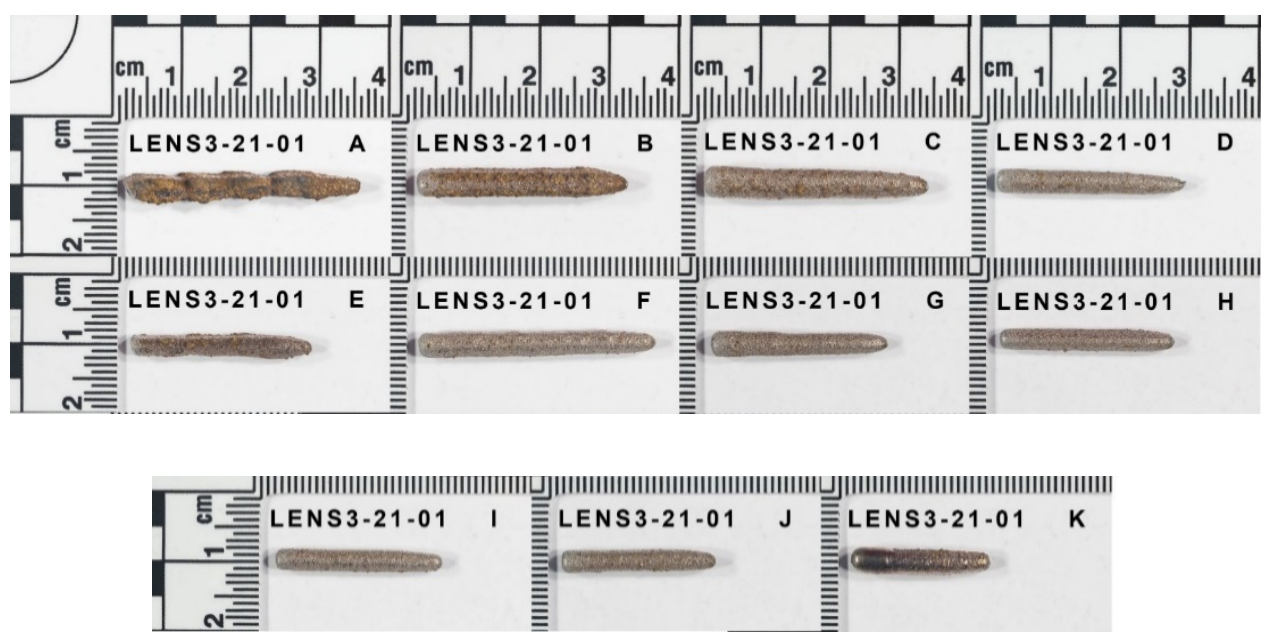

Figure 5. Full-Co DED samples A-K laid down horizontally for comparison. The right side of each sample was the point of connection to the build plate and the left side is the free end (top of the rod, i.e., build direction left). 


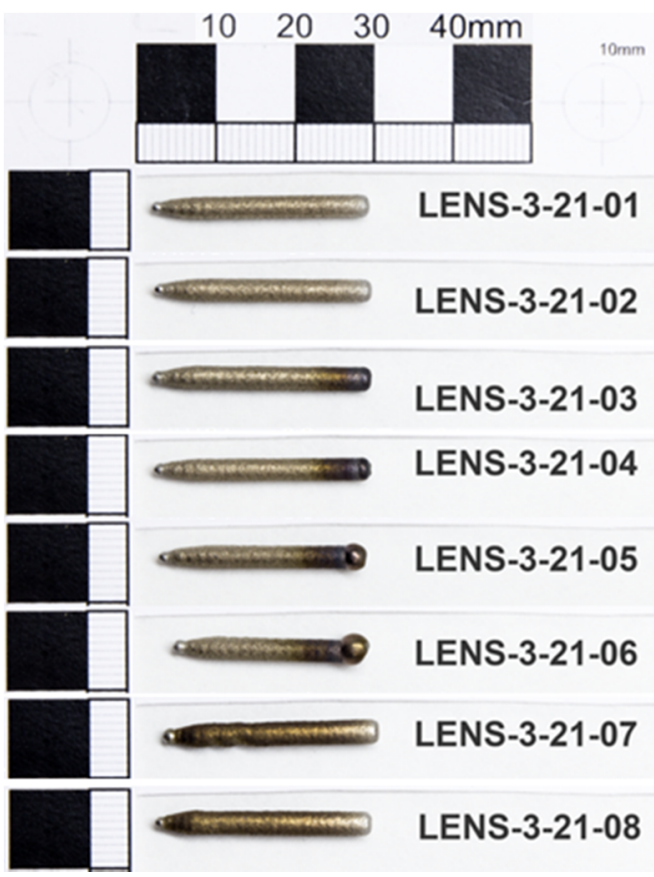

Figure 6. Co-Lean DED samples 1-8 laid down horizontally for comparison. The left side of each sample was the point of connection to the build plate and the right side is the free end (top of the rod, i.e., build direction right). The left-hand scale bar represents $10 \mathrm{~mm}$.

\subsubsection{Microstructure}

Samples were vertically cross-sectioned and examined for microstructural features. Analysis of the full-Co samples is included in Figures 7-9 while the Co-lean microstructural details are presented in Figures 10-12. There was low deviation between samples by this method and a representative microstructure of a full-Co sample is included below in Figure 7, and a representative microstructure of a Co-lean sample is included below in Figure 10. Throughout the cross-sections an equiaxed microstructure was prevalent with a finer grain "skin" (thickness of $\sim 200-260 \mu \mathrm{m}$ for full-Co), which was thinner than previous alnico DED builds, including the Co-lean in this study [16]. Increasing the grain aspect ratio along the vertical (build) direction is preferred, and would be beneficial towards increasing the magnetic remanence and energy product values.

Investigation of any preferential grain orientation was performed for both compositions and the orientation information is presented in Figures 7 and 10 as an overlay of the grain orientation on a low magnification SEM micrograph. Quantitative orientation information in the form of pole figures (PF) and inverse pole figures (IPF) is included for each composition in Figures 8 and 11. According to the EBSD maps and IPF of the samples, there was no significant texture evident. Investigation of the microstructure present after the post-build SOQ process, the grain structure that persists during the MA and FHT processes, was conducted and is included in Figures 9 and 12. Note the uniform grain growth that occurs in both the Co-lean and full-Co compositions. 

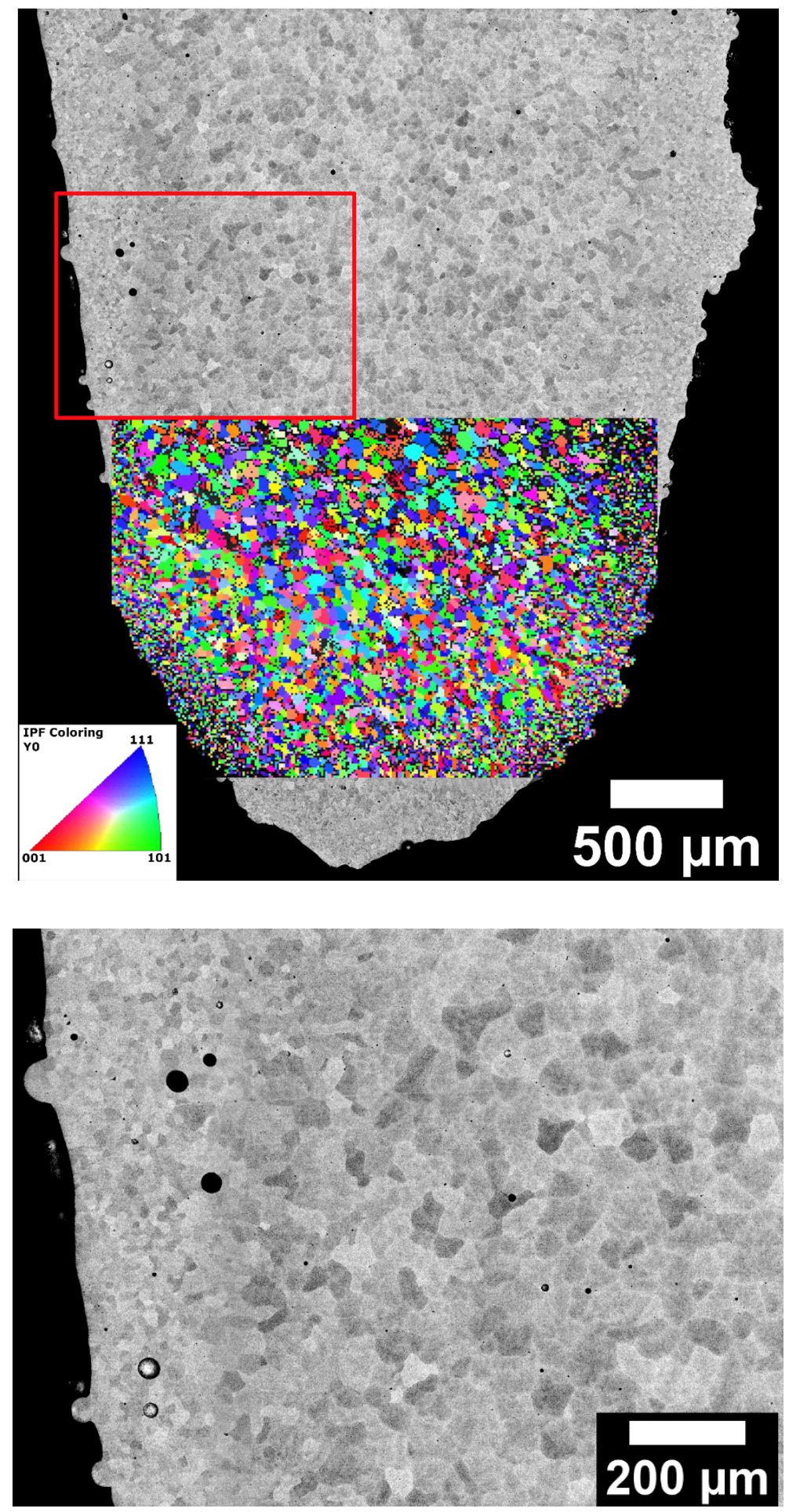

Figure 7. SEM images of the DED full-Co alnico build sample C (build direction up) with corresponding EBSD map (top) and higher magnification image of a selected edge region (bottom). 

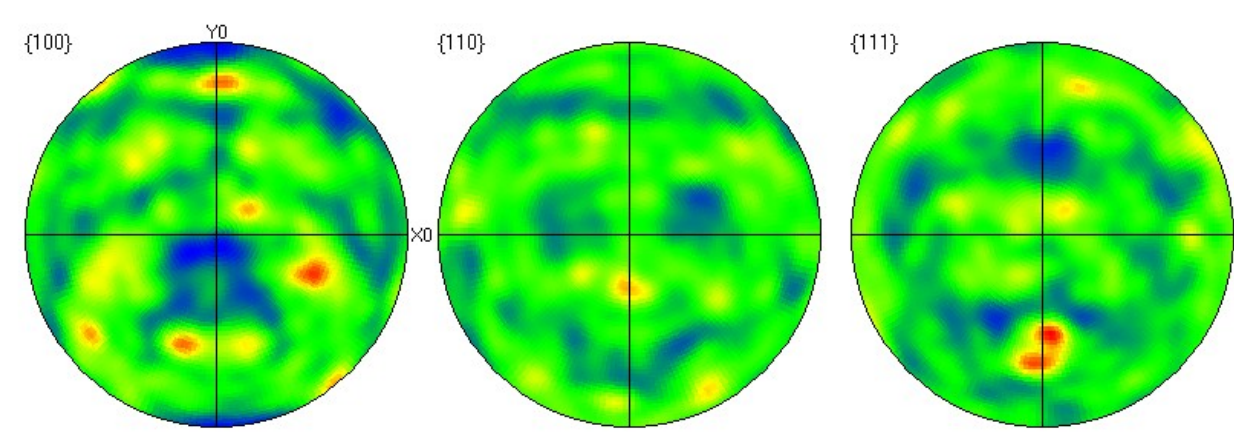

$\times 0$

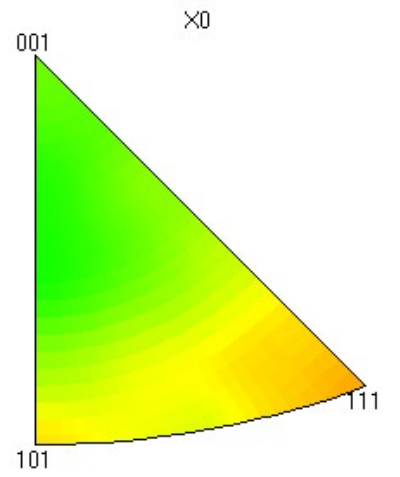

Yo

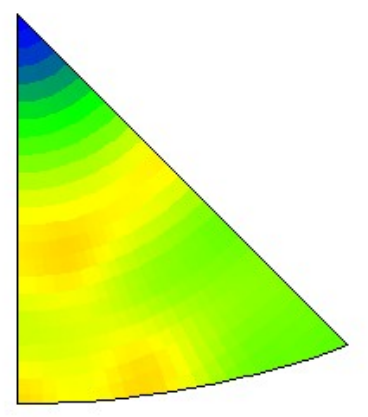

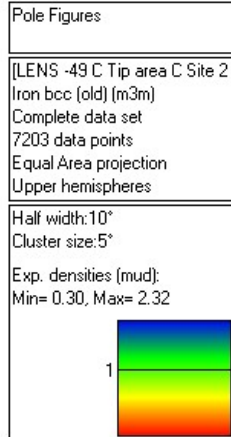

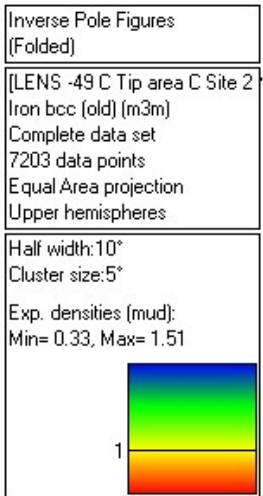

Figure 8. Orientation information from the region of DED sample $C$ shown in Figure 7 with PFs for the $\{100\},\{110\}$, and $\{111\}$-type planes (top) and IPFs for the sample $X, Y$, and $Z$ directions (bottom). Of note is the lack of apparent texturing.

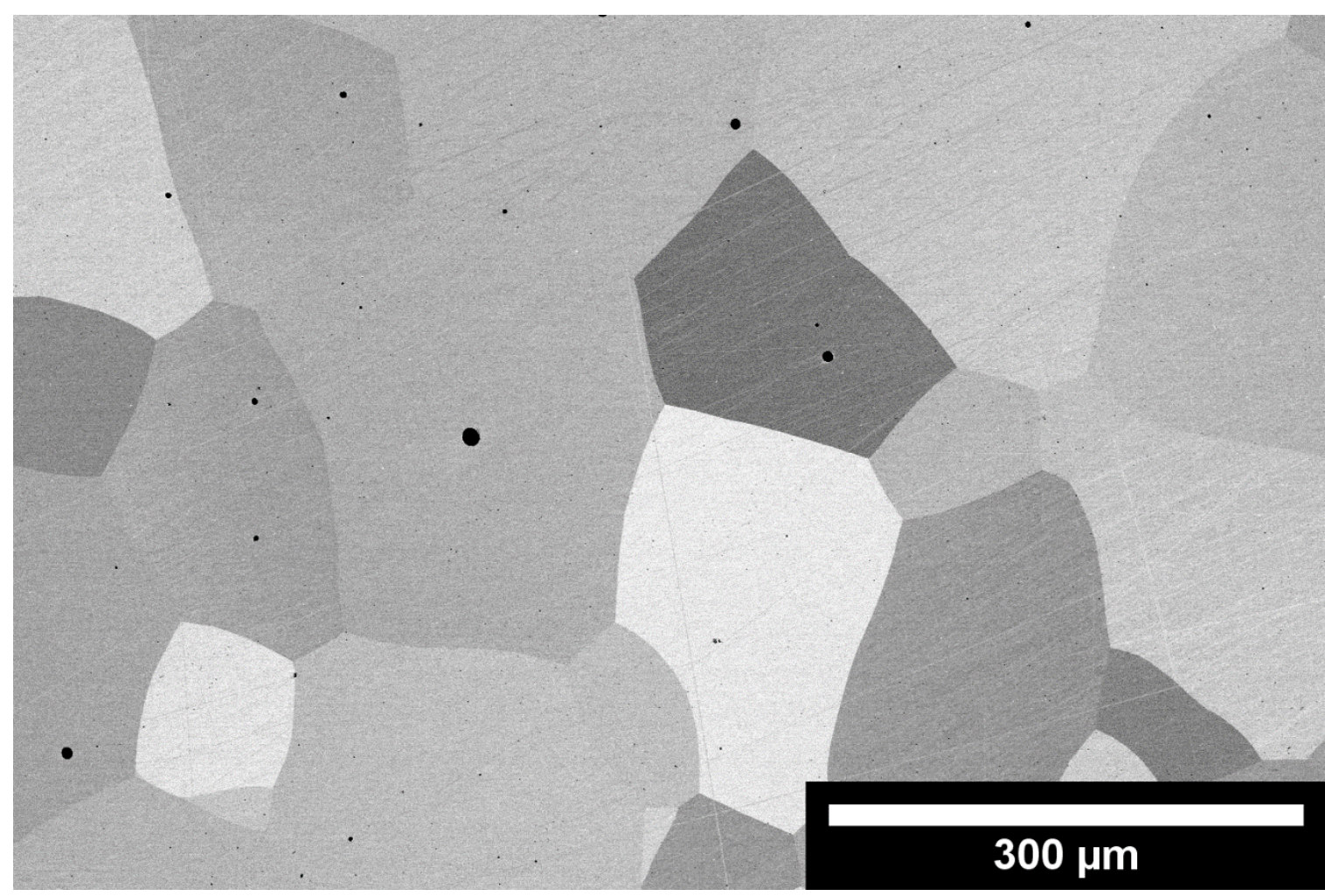

Figure 9. Post SOQ microstructure of sample C, DED AM fabricated full-Co alnico. 


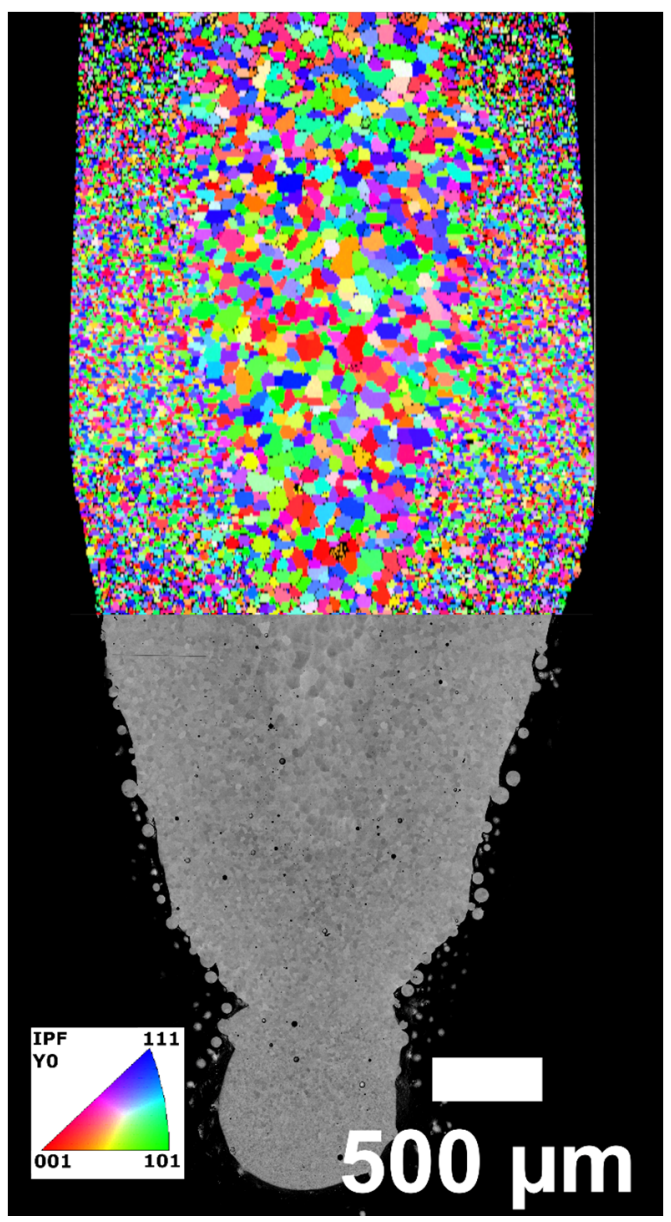

Figure 10. SEM image of the DED Co-lean alnico build sample 8 (build direction up).

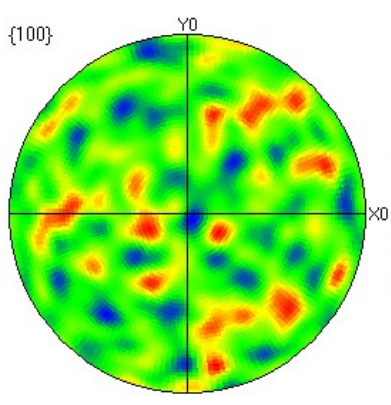

$\times 0$

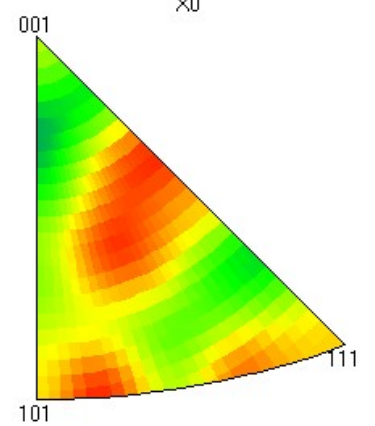

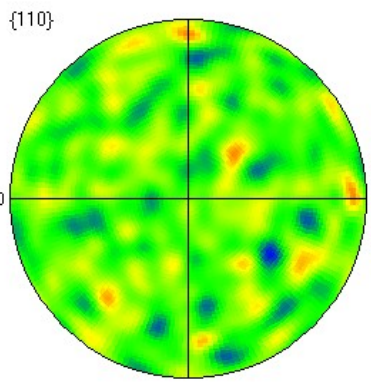

YO

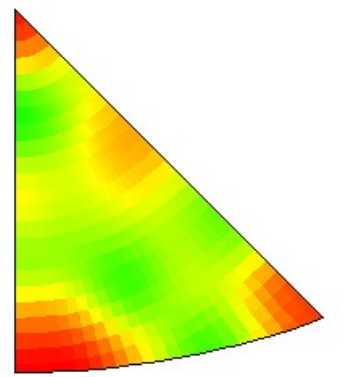

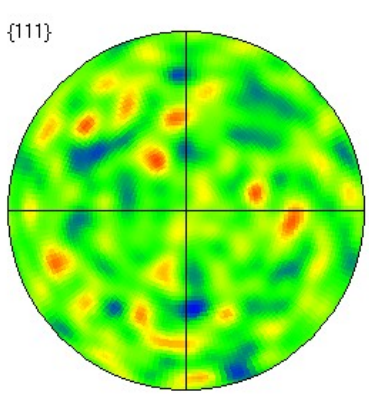

20

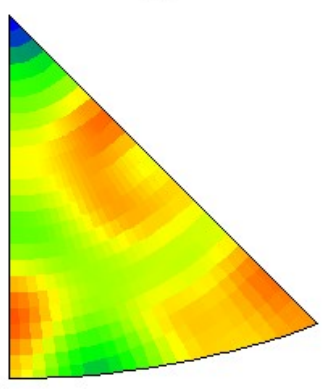

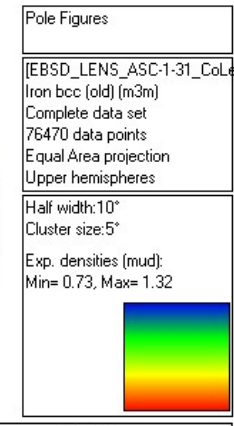

\begin{tabular}{|l|}
\hline $\begin{array}{l}\text { Inverse Pole Figures } \\
\text { (Folded) }\end{array}$ \\
\hline [EBSD_LNS_ASC-1.31_CoL \\
\hline
\end{tabular}

[EBSD_LENS_ASC-1.31-
iron bcc (old) (m3m) Complete data set 76470 data points Jpper hemispheres Half width: $10^{*}$ Cluster size: $5^{\star}$ Exp. densities (mud): Min $=0.82$, Max= 1.09

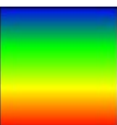

Figure 11. Orientation information from the region of the Co-lean sample 8 shown in Figure 10 with PFs for the $\{100\},\{110\}$, and $\{111\}$-type planes (top) and IPFs for the sample $X, Y$, and $Z$ directions (bottom). Of note is the lack of apparent texturing. 


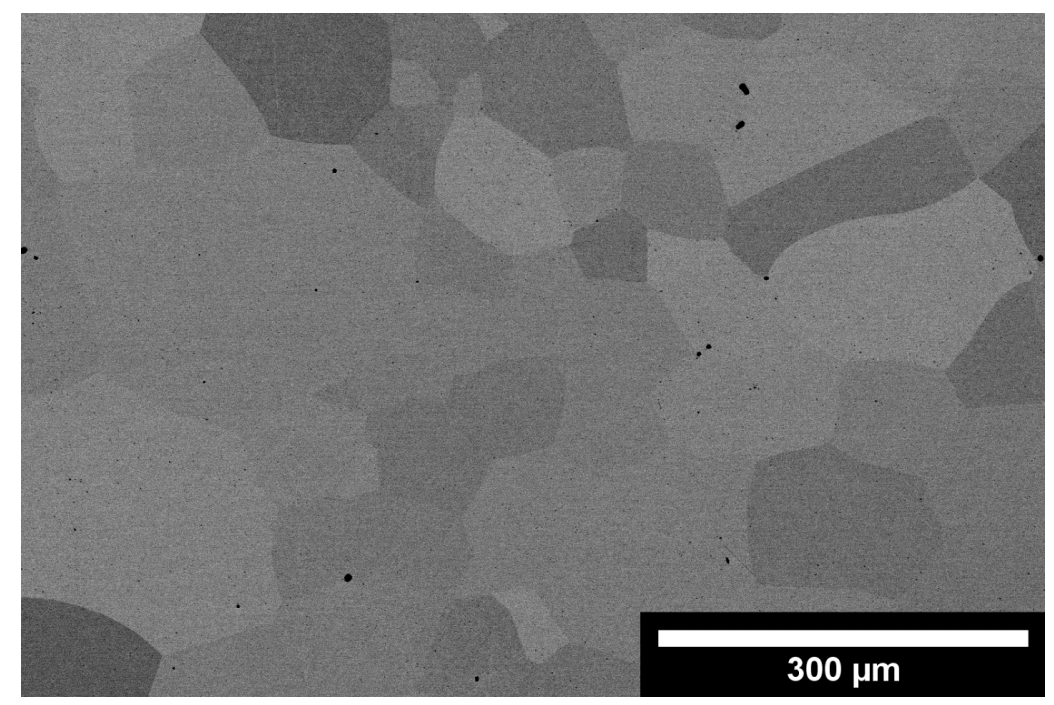

Figure 12. Co-lean sample 8 after SOQ processing. Note the increase in gran size from the as-built case.

\subsubsection{Density}

After EDM and centerless grinding, the cylindrical samples were measured and massed to compute the geometrical density. Table 6; Table 7 report the geometrical density for the DED samples of the full-Co and Co-lean, respectively. Table 8 reports the geometrical density of the EBM/PBF samples. Note in Table 6 that only two of the three cylinders machined from sample B were of sufficient quality for MA (the full-Co DED samples), hence the presence of only two samples despite the "B-3" label.

Table 6. Geometrical density of full-Co DED alnico post machined cylinders.

\begin{tabular}{cc}
\hline Sample & Density $\left(\mathrm{g} / \mathbf{c m}^{\mathbf{3}}\right)$ \\
\hline B-2 & 7.24 \\
B-3 & 7.22 \\
C-1 & 7.21 \\
C-2 & 7.25 \\
F & 7.25 \\
G & 7.21 \\
K & 7.23 \\
\hline
\end{tabular}

Table 7. Geometrical density of Co-lean DED alnico post machined cylinders.

\begin{tabular}{cc}
\hline Sample & Density $\left(\mathrm{g} / \mathbf{c m}^{3}\right)$ \\
\hline $1-1$ & 7.19 \\
$1-2$ & 7.22 \\
$2-1$ & 7.18 \\
$2-2$ & 7.28 \\
$3-1$ & 7.19 \\
$3-2$ & 7.18 \\
$4-1$ & 7.22 \\
$4-2$ & 7.18 \\
$5-1$ & 7.15 \\
$5-2$ & 7.15 \\
$6-1$ & 7.24 \\
$6-2$ & 7.23 \\
$7-1$ & 7.22 \\
$7-2$ & 7.22 \\
$8-1$ & 7.21 \\
$8-2$ & 7.25 \\
\hline
\end{tabular}


Table 8. Geometrical density of Co-lean EBM/PBF alnico post machined cylinders.

\begin{tabular}{cc}
\hline Sample $\left(\mathbf{M A}\right.$ time $(\mathbf{m i n}) / \mathbf{M A}$ temperature $\left.\left({ }^{\circ} \mathbf{C}\right)\right)$ & Density $\left(\mathbf{g} / \mathbf{c m}^{\mathbf{3}}\right)$ \\
\hline $8 / 830$ & 7.26 \\
$8 / 850$ & 7.24 \\
$8 / 870$ & 7.26 \\
$4 / 830$ & 7.20 \\
$4 / 850$ & 7.26 \\
$4 / 870$ & 7.27 \\
$1 / 830$ & 7.25 \\
$1 / 850$ & 7.20 \\
$1 / 870$ & 7.26 \\
\hline
\end{tabular}

\subsubsection{Magnetic Properties}

Samples B, C, F, G and K of Table 6 were $>3 \mathrm{~mm}$ diameter consistently across their length which enabled magnetic property testing of these full-Co samples after MA and FHT, as shown in Table 9. Multiple samples were taken from samples B and C due to their length and are listed accordingly. The increased diameter of the built cylinders permitted equiaxed, fine grain "skin" removal during cylinder fabrication, potentially improving magnetic properties. However, it should be noted that the cylinder microstructure going into the MA and FHT process consisted of the microstructure shown in Figure 9. Past investigations have shown how sensitive the FHT optimization and resulting magnetic properties are to the processing steps and the starting microstructure for essentially all cast, sintered, and/or DED alnico samples. Thus, the limited number of DED samples for a given set of AM processing parameters prevented extensive optimization [16,28]. A limited MA optimization $\left(+5{ }^{\circ} \mathrm{C}\right)$ was attempted (with a constant FHT) for the sample listed as C-2, compared to sample C-1. The cast sample also underwent an optimization test $\left(-5^{\circ} \mathrm{C}\right)$.

Table 9. FHT Magnetic properties of full-Co DED processed alnico build samples and comparison with baseline sintered and cast samples.

\begin{tabular}{ccccc}
\hline Sample & Br (kG) & HcJ (Oe) & BHmax (MGOe) & Ms (kG) \\
\hline Sintered (12 h) & 7.36 & 2061 & 4.50 & 10.60 \\
Cast & 6.60 & 2428 & 4.69 & 10.40 \\
B-2 & 7.35 & 2110 & 4.90 & 10.87 \\
B-3 & 6.86 & 2022 & 4.09 & 10.22 \\
C-1 & 6.75 & 2034 & 4.06 & 10.19 \\
C-2 & 6.81 & 2037 & 4.12 & 10.18 \\
F & 6.79 & 2050 & 4.06 & 10.52 \\
G & 6.59 & 1953 & 3.50 & 10.40 \\
K & 6.80 & 2036 & 3.96 & 10.27 \\
\hline
\end{tabular}

For the full-Co, the highest remanence value was seen for the B-2 sample and is comparable to the sintered samples of the same powder and higher than that of the (isotropic) cast sample. This improved remanence value is typically an indication of increased texturing of the build microstructure, but this was not obvious in the EBSD results, when compared to the results from sample C in Figure 7; Figure 8. The highest coercivity value of the DED samples was also the B-2 sample at 2110 Oe, slightly exceeding the coercivity of the baseline sintered samples, yet lower than the cast sample. Thus, the highest energy product of the DED samples was also the B-2 sample at 4.90 MGOe, improving upon the sintered sample and cast energy product of 4.50 MGOe and 4.69 MGOe, respectively. The rest of the full-Co DED samples in Table 9 were close in remanence, coercivity and energy product (with the exception of sample G), indicating very small deviation in magnetic properties as a function of DED processing parameters. This finding is very beneficial for AM processing of complex geometries and indicates a high buildability of the alnico material. 
Similar to the full-Co, the Co-lean as-built DED samples were $>3 \mathrm{~mm}$ diameter rough cylinders (see Figure 6 and Table 7) consistently along their length which enabled machining to the proper dimensions for magnetic property testing after MA and FHT, as shown in Table 10. Unlike the full-Co, the diameters of the as-built parts were smaller than that of the full-Co. This slightly decreased diameter resulted in the fine grain "skin" (see Figure 10) to remain within the final machined cylinder samples, potentially impacting magnetic properties. However, it should be noted that the cylinder microstructure going into the MA and FHT process consisted of the microstructure shown in Figure 12, showing similar grain growth behavior to the full-Co DED samples. Two cylinders were extracted from each as-built specimen, and similar to the full-Co composition, there was limited capability to explore MA and FHT parameters with these Co-lean samples. Thus, the same MA and FHT was completed on all of the cylinders (including the sintered and cast). Just as observed with the full-Co DED specimens, as the AM processing parameters changed, there was not a large spread of the magnetic properties in the Co-lean samples. Coercivity of these samples when compared to sintered and cast counterparts, was highest in the cast specimen followed by DED and then sintering. Co-lean DED remanence values only outperformed (Table 10) the cast and sintered counterparts in one case (sample 2-1); however, overall the sintered and cast samples outperformed the Co-lean DED samples. As for the energy product, both the cast and sintered specimens outperformed the Co-lean DED samples. Although magnetic properties were overall not up to the cast and sintered samples, the consistency from sample to sample as the AM parameters changed should be worth noting. This consistency trend is present in the DED samples, regardless of composition.

Table 10. FHT Magnetic properties of Co-lean DED processed alnico build samples and comparison with baseline sintered and cast samples.

\begin{tabular}{|c|c|c|c|c|}
\hline Sample & Br (kG) & HcJ (Oe) & BHmax (MGOe) & Ms (kG) \\
\hline Sintered (12 h) & 7.50 & 1660 & 4.30 & 10.40 \\
\hline Cast & 7.50 & 2231 & 5.62 & 10.60 \\
\hline $1-1$ & $7.06 / 7.81$ & $2021 * 1833$ & $3.72 * 3.80$ & 11.03 \\
\hline $1-2$ & $7.38 / * 8.14$ & $2036 /{ }^{*} 1894$ & $3.86 / * 3.87$ & 11.13 \\
\hline $2-1$ & $7.56 / * 7.20$ & $2098 / 1914$ & $4.22 / 3.84$ & 11.12 \\
\hline $2-2$ & $7.25 / * 7.44$ & $2095 / * 1871$ & $4.12 / * 3.97$ & 11.13 \\
\hline $3-1$ & 6.70 & 1865 & 3.30 & 10.90 \\
\hline $3-2$ & 7.21 & 1989 & 3.94 & 11.15 \\
\hline $4-1$ & 7.02 & 1938 & 3.38 & 11.04 \\
\hline $4-2$ & 6.87 & 1924 & 3.38 & 11.09 \\
\hline $5-1$ & 7.40 & 1983 & 3.93 & 11.03 \\
\hline $5-2$ & 7.12 & 2008 & 3.81 & 10.94 \\
\hline $6-1$ & 6.68 & 1878 & 3.31 & 11.03 \\
\hline $6-2$ & 7.21 & 2082 & 4.22 & 11.08 \\
\hline $7-1$ & 6.69 & 1972 & 3.60 & 11.03 \\
\hline $7-2$ & 6.81 & 1972 & 3.70 & 11.08 \\
\hline $8-1$ & $7.04 / * 7.48$ & $2106 / 2011$ & $4.12 / * 4.5$ & 11.09 \\
\hline $8-2$ & $7.03 / * 7.07$ & $2100 / 1986$ & $4.09 / * 4.01$ & 10.95 \\
\hline
\end{tabular}

* adjusted SOQ processing parameters.

\subsection{EBM/PBF Additive Manufacturing}

\subsubsection{Process Optimization}

Photographs of the EBM/PBF samples for each of the five optimization iterations are shown in Figure 13. The somewhat high observed sintering temperature of the alnico powders $\left(\sim 1100{ }^{\circ} \mathrm{C}\right)$ is relatively close to the melting temperature of the material $\left(\sim 1257^{\circ} \mathrm{C}\right)$, leading to difficulty in maintaining a consistent heat flux through the build chamber without over-sintering the powders during preheating. Surface temperatures below $\sim 900{ }^{\circ} \mathrm{C}$ were observed to be susceptible to charge induced powder scattering events (i.e., "smoking" [29-31]), one cause of premature failure of these runs. On the other hand, 
over-sintering would cause the entire layer to curl and separate from the powder bed, and the resulting vacuum gap breaks the conductive pathway and exacerbates the effect. For run \#3, the $304 \mathrm{SS}$ substrate was replaced with a Ti-6Al-4V substrate with the idea that the lower thermal conductivity of Ti-6Al-4V ( $\sim 7 \mathrm{~W} / \mathrm{mK}$, vs. $\sim 15 \mathrm{~W} / \mathrm{mK}$ for $304 \mathrm{SS})$ would help maintain a higher surface temperature in the build region. Run \#3 eventually swelled from excessive heat input and was halted when the surface asperities interfered with the powder spreading. Run \#4 utilized a higher surface temperature, lower beam currents and a higher base beam speed, and this resulted in a relatively stable build temperature and smooth, flat layering. These parameters were chosen as the basis for the larger sample in run \#5, which was sized for magnetic property analysis.

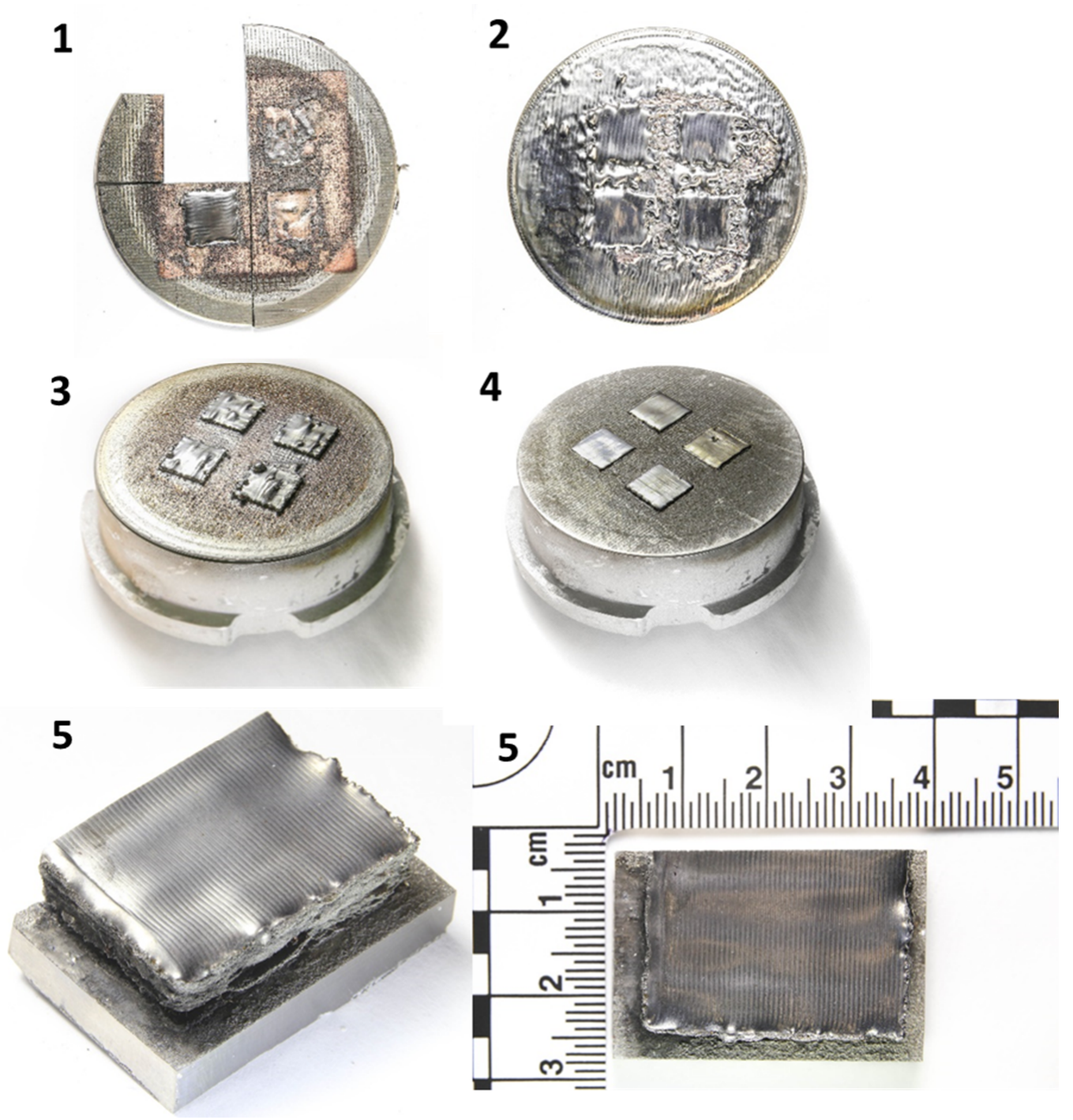

Figure 13. Photographs of (1-4) successive build trials and (5) the first successful PB-EBF build of alnico to a height of approximately $8 \mathrm{~mm}$. Sample 1 was cut into sections for initial analysis not included here. 
During run \#5, a second melting step using a defocused beam was added to each layer to improve the flatness of each layer and facilitate improved layering. Table 11 shows the chemistry of the sample produced in run \#5 determined via XRF and EDS and at various points of processing (raw powder and after SOQ). Apparent from these results is that significant volatilization of aluminum has occurred during the EBM/PBF process, which is not unexpected given the high temperatures required to achieve process stability (e.g., proper sintering of the powder). Additionally, initial run parameters, especially run \#1, indicated $\mathrm{Cu}$ segregation or deposition on the substrate during EBM/PBF processing.

Table 11. Composition data for the EBM/PBF sample from run \#5.

\begin{tabular}{cccccccc}
\hline at. $\%$ & Fe & $\mathbf{A l}$ & $\mathbf{N i}$ & $\mathbf{C o}$ & $\mathbf{C u}$ & $\mathbf{T i}$ & $\mathbf{N b}$ \\
\hline As-Received Powder CPP $^{2}$ & 30.64 & 14.31 & 14.54 & 29.05 & 2.58 & 8.55 & 0.33 \\
As-built, XRF ${ }^{+}$ & 29.66 & 7.80 & 18.00 & 32.81 & 0.379 & 9.34 & 1.52 \\
As-built, EDS & 26.52 & 12.14 & 19.33 & 31.07 & 1.41 & 8.89 & 0.55 \\
SOQ, EDS & 26.7 & 12.07 & 19.10 & 31.00 & 1.69 & 8.82 & 0.54 \\
\hline
\end{tabular}

${ }^{+} \mathrm{XRF}$ data accurate to at least \pm 0.2 .

\subsubsection{Microstructure}

Initial micrographs were taken of the early builds (1-4) in Figure 13 however these are not included as the microstructures revealed that the height of the build was not sufficient to mitigate influence from the build plate including grain size and compositional contamination. Run \#5 with the improved parameter set allowed enough sample height to be beyond substrate influence.

The as-built refined equiaxed microstructure of EBM/PBF run \#5 is shown in detail in Figure 14 and is observed throughout the sample. Elemental mapping with EDS confirmed compositional segregation at the grain boundaries; in particular $\mathrm{Fe}, \mathrm{Al}$, and $\mathrm{Ti}$ had been depleted indicating the formation of the $\gamma$-phase (similar to the FCC $\gamma$-Fe or Fm $\overline{3} \mathrm{~m}$ crystal structure) $[6,32]$ which is detrimental to magnetic properties and forms upon slower cooling within the EBM/PBF chamber. Suppression of the $\gamma$-phase occurs with solutionization and oil quenching, as shown in Figure 15, indicating the as-built EBM/PBF samples still require this step due to the slower cooling rate, similar to traditionally processed alnico. Figure 15 also indicates that grain growth occurs in these Co-lean EBM/PBF samples during the post-build SOQ, consistent with the DED samples as shown in Figure 12.

As can be seen from the micrograph and the IPF coloring in Figure 16, as well as the IPFs included in Figure 17, there exists slight texturing across the EBM/PBF specimen. However, in the build direction the slight amount of texturing is evident in the $<111>$ direction. There is no strong texturing in the desired $<001>$ crystallographic orientation for this alnico composition and corresponding set of $\mathrm{EBM} / \mathrm{PBF}$ processing parameters. 


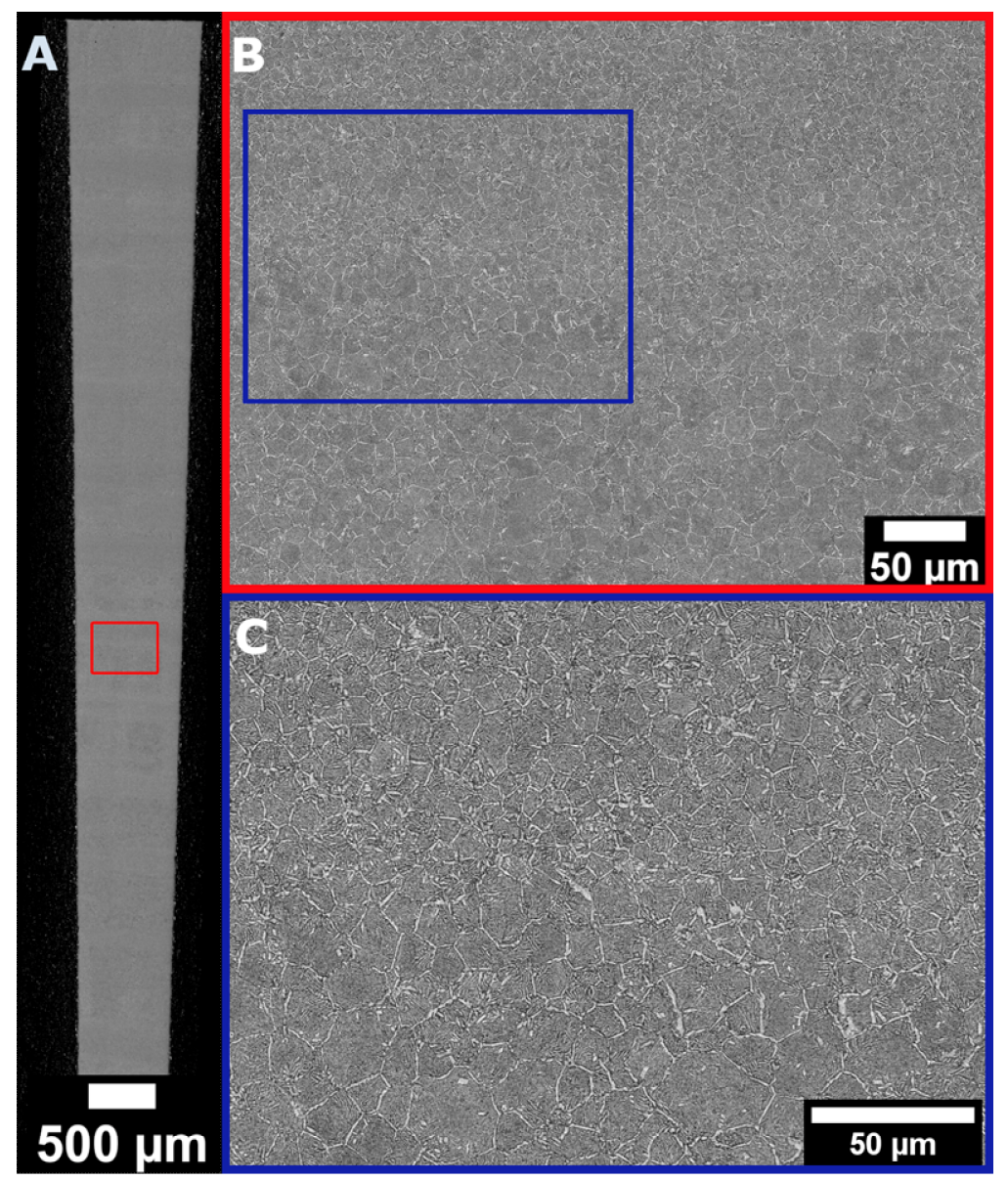

Figure 14. Micrographs of an as-built transverse section between the magnetic cylinder samples (i.e., build direction is out of the plane). (A) Macro image of the entire specimen, where a subtle layered structure variation may be seen in the horizontal direction. (B) Magnified region with variations in grain/cellular size apparent. (C) Higher magnification micrograph with clear eutectic formation inside cellular boundaries and an elevated amount of the $\gamma$-phase at every cell boundary.

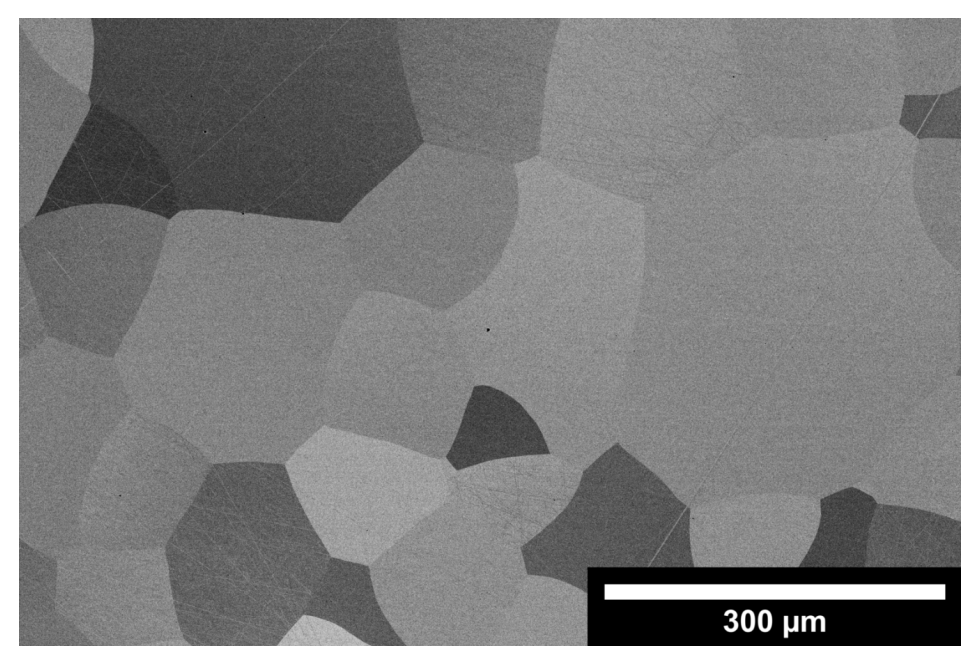

Figure 15. SEM micrograph of one of the cylinder sections after SOQ at $1210{ }^{\circ} \mathrm{C}$ for $30 \mathrm{~min}$ and oil quenching. 


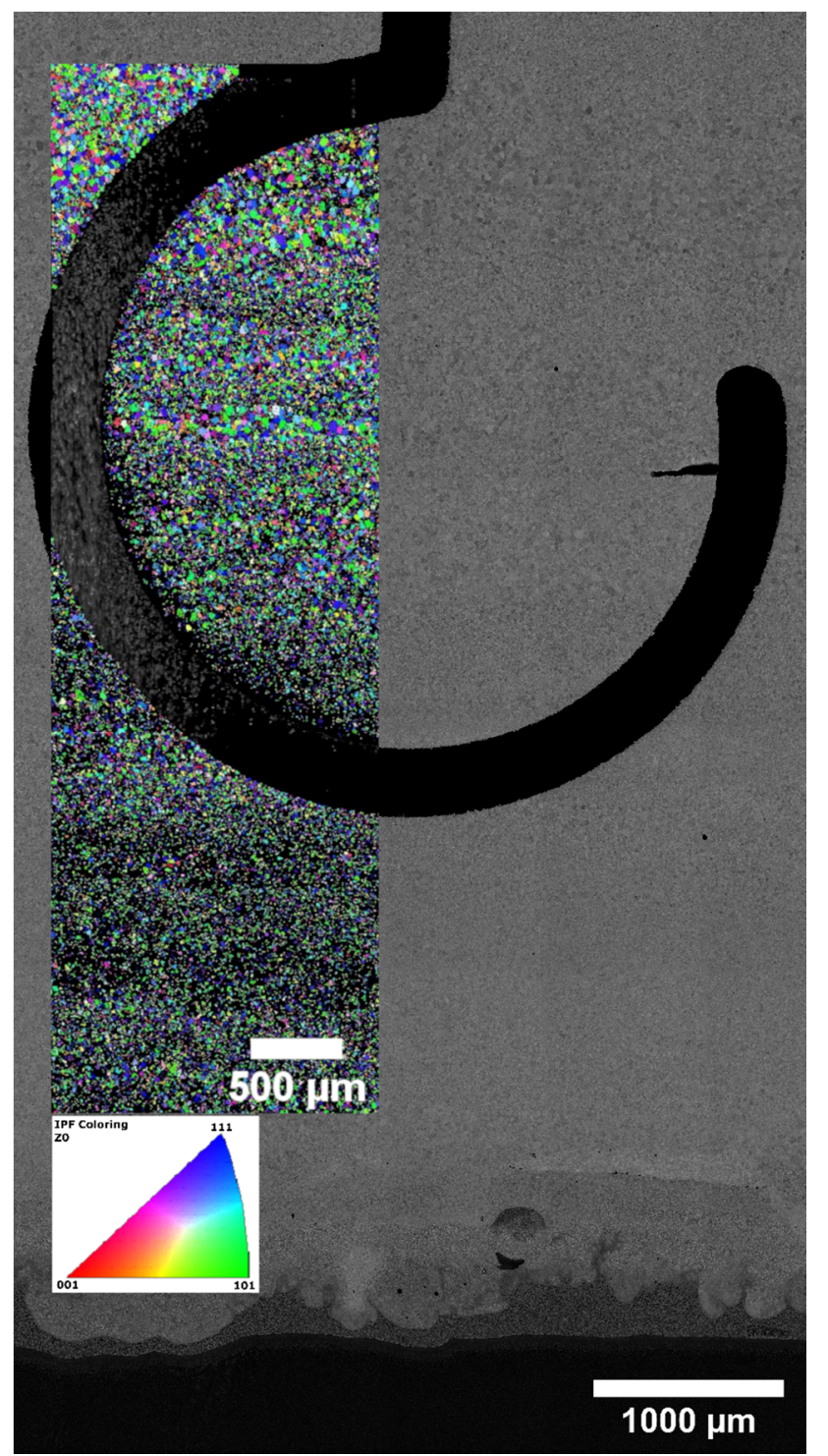

Figure 16. SEM micrograph of the ROI as identified in Figure 2 with IPF coloring overlay. Build direction is oriented towards the top of the image. The dark regions forming a "fish-hook" shape is where the EDM wire had removed material before the wire broke.
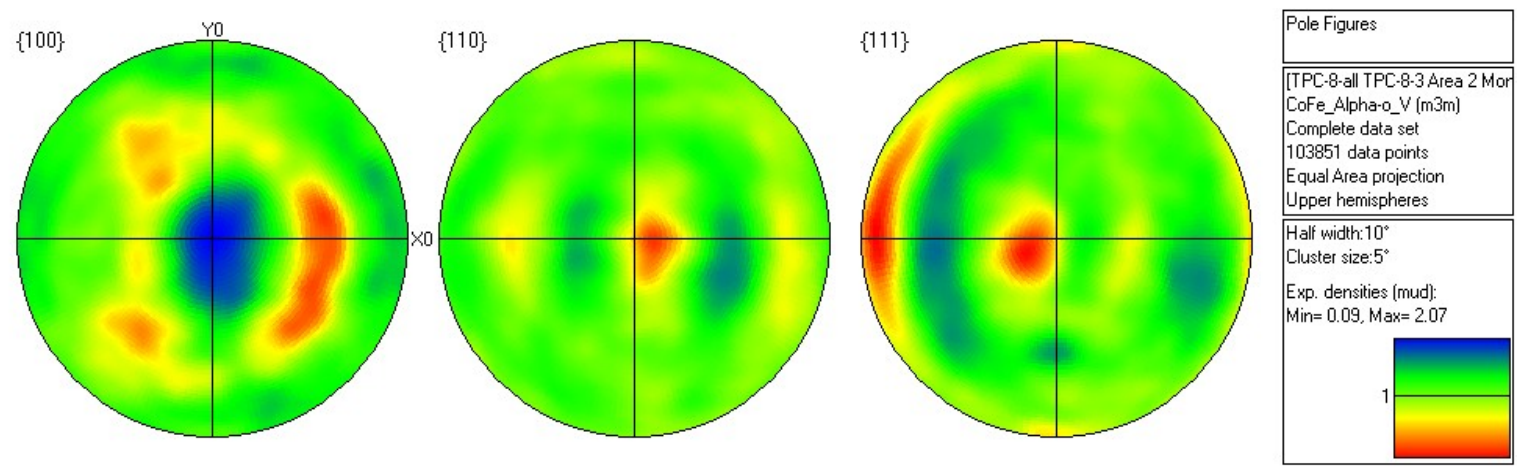

Figure 17. Cont. 

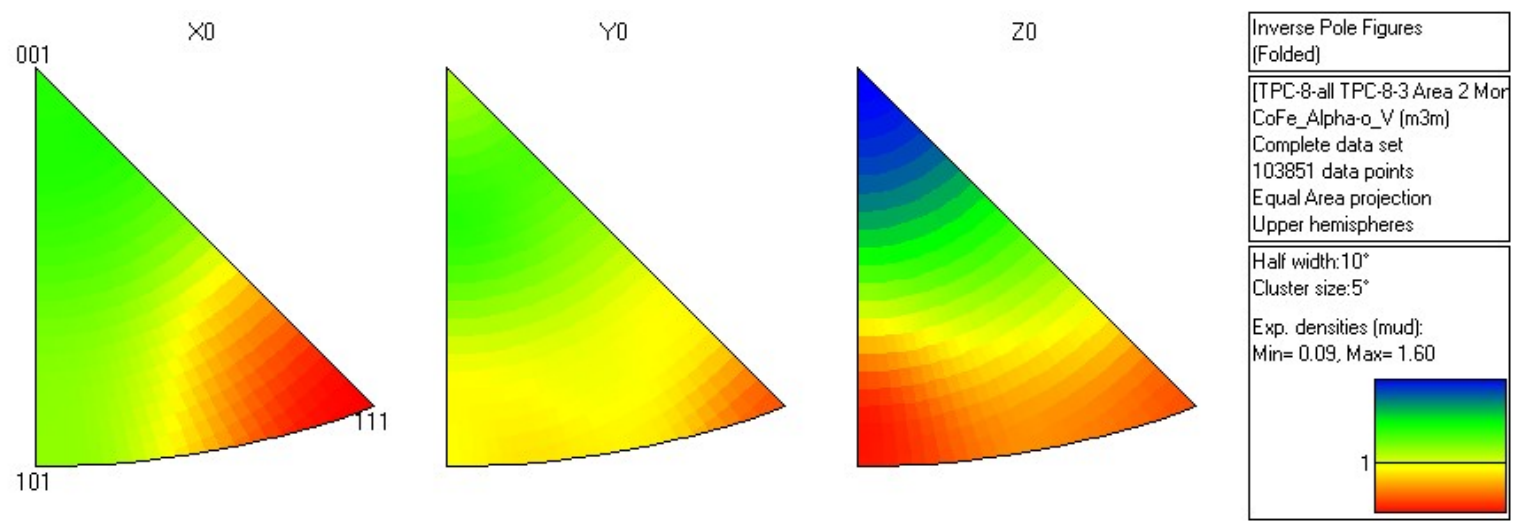

Figure 17. Orientation data from region in Figure 16 with PFs of $\{100\},\{110\}$, and $\{111\}$-type planes projected in the sample $X$ and $Y$ directions (top) and IPFs for X, Y, and Z sample directions (bottom). Note minor texturing is evident.

\subsubsection{Magnetic Properties}

The number of EBM/PBF alnico samples allowed for magnetic properties to be studied (Figure 18; Figure 19) for various MA temperatures and hold times. The MA, which is responsible for establishing the initial nanostructure, was varied between $830^{\circ} \mathrm{C}, 850^{\circ} \mathrm{C}$ and $870^{\circ} \mathrm{C}$ and for 1,4 and $8 \mathrm{~min}$. The FHT process further increases the magnetic properties regardless of the MA process and has been studied in detail elsewhere [28]. It should be noted that Figure 18; Figure 19 are plotted with respect to the MA temperature or hold time.

The highest coercivity was achieved by MA at $870{ }^{\circ} \mathrm{C}$ for $8 \mathrm{~min}$, while all the times at $870{ }^{\circ} \mathrm{C}$ gave the lowest remanence values-a tradeoff common in permanent magnet materials. The highest remanence values were seen at the lower temperatures of $830^{\circ} \mathrm{C}$ and $850^{\circ} \mathrm{C}$, almost independent of time. The sintered specimens of this composition showed optimal magnetic properties for $8 \mathrm{~min}$ at $830^{\circ} \mathrm{C}$, confirming that the FHT for the EBM/PBF samples must be independently optimized from their sintered and cast counterparts.
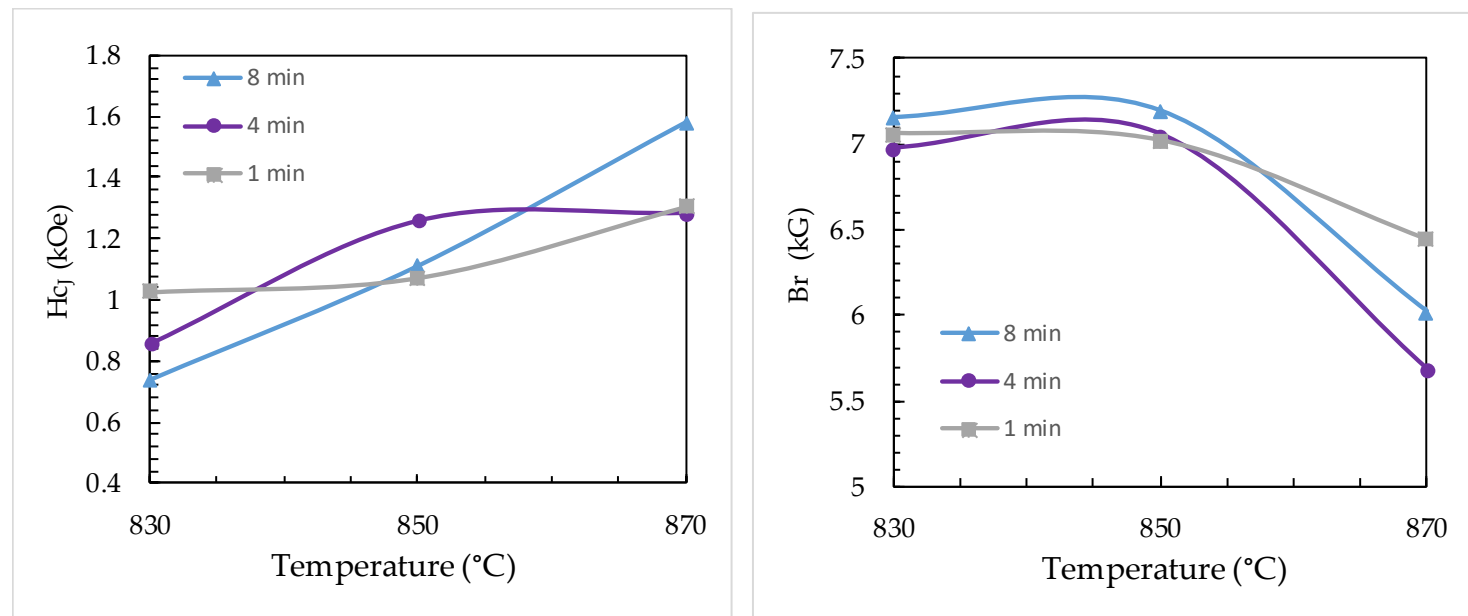

Figure 18. Coercivity and remanence of the EBM/PBF run\#5 samples as a function of temperature for different MA hold times. FHT were kept identical between all samples. 


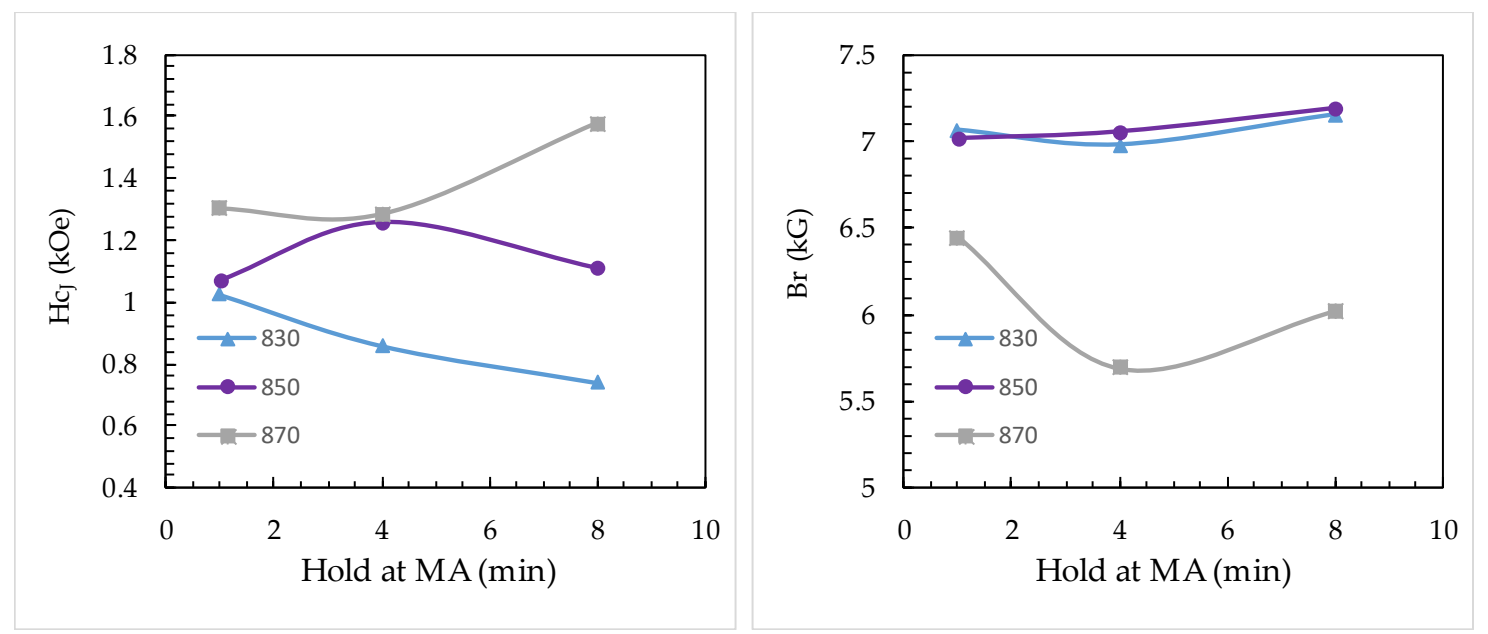

Figure 19. Coercivity and remanence of the EBM/PBF run\#5 samples as a function of hold length for different MA temperature. FHT were kept identical between all samples.

\section{Discussion}

To investigate if the AM processing parameters would impact resulting magnetic properties, DED samples of different build parameters were created and the same SOQ, MA and FHT were completed on all of the samples of the same composition. Overall, as the AM parameters varied, no large shift occurred in the final magnetic properties in the full-Co alloy nor in the Co-lean alloy (see Table 9; Table 10), with the exception of the full-Co B-2 sample. The lack of strong texture in both compositions of the as-printed DED samples is also likely a source of the consistent magnetic properties across AM processing parameters. Possible minor $<001>$ texturing could be the reason why the full-Co B-2 sample had superior magnetic properties; however this would have to be concluded with destructive analysis (i.e., cross section and polishing) of the B-2 sample. It is worth noting that during the SOQ process of both alloys that were built by DED, accelerated, uniform grain growth occurred in both the Co-lean and full-Co. The grain growth that was observed is likely a product of residual stresses in the as-printed specimens. This uniform grain growth is beneficial for the coercivity since larger grains would suppress the total volume of grain boundaries present, limiting the total $\gamma$-phase that could form during the MA heat treatment [6]. Future, more complete investigation of the SOQ parameters will be conducted to reach larger grain sizes. Additionally, powder-based alnico magnets can achieve enhanced texture control in the presence of uniform uni-axial stress, thus future investigations could be attempted to utilize the residual stresses from the as-printed state to promote the texture of the post-SOQ microstructure in the desired $<001>$ direction [33]. If a $<001>$ texture could be developed utilizing the preexisting residual stress, the DED AM method could be part of a logical approach to fully textured alnico magnets.

The challenges of build cracking, porosity and defects seen in some materials processed via DED were not evident in these sets of alnico samples. Two different compositions were successfully built over a range of processing parameters, albeit some parameters resulted in qualitatively better builds. Other advanced systems and controls, including laser PBF, could be applied to further optimize the build quality and microstructure of this alnico family of permanent magnet materials, which have proven their potential for being processed by the laser DED method of AM.

The focus of most EBM/PBF AM process development research is on the combination of melting parameters (beam speed, power, overlap, etc.) that will lead to dense components. The significant influence of spot size variation on local energy density across the build area, which is difficult to directly measure in situ, is generally not known but can be inferred from corresponding variation in density associated with the known effects of changes in beam focus. Similarly, the preheating parameters are rarely reported. In EBM/PBF the transfer of energy and charge from the beam to the powder bed are 
inherently coupled. Without sufficient dissipation of charge and adequate preheating, electrostatic repulsion will overcome the mass of discrete adjacent powder particles causing a catastrophic scattering of charged powder throughout the build chamber (i.e., "smoking"). Within the powder bed the objective is for the powder to be lightly sintered (i.e., the initial stages of necking). This both dissipates charge by forming an electrically conductive pathway to ground within the powder bed and by providing mechanical resistance to electrostatic repulsion by powder charging. Thus, preheating to have the proper amount of light sintering is necessary to maintain process stability. In the EBM/PBF preheat step the powder is heated by strategically scanning a relatively high power, high speed and defocused beam over the surface until sufficient temperature is reached to overcome the activation energy for sintering. The combination of parameters in the preheat step (e.g., line order, line offset, beam focus and beam speed) are tailored in such a way to add sufficient heat to the system to raise the temperature of the surface of the powder bed, while also allowing sufficient time for charge to dissipate between line scans until the powder is sintered. Only recently has work by Cordero et al. modeled these charge and heating/sintering effects for a mono layer of spherical metallic powder with an oxide layer during preheating [31]. However, the local variations in particle size distribution, morphology oxide thickness in typical AM powders significantly complicate the prediction of the onset of scattering and require further investigation.

While not the initial focus of this study, it became apparent in the early stages of the development effort that the initial challenge with EBM/PBF of alnico powder was to identify a stable processing space for preheating of the powder bed of this magnetic material, while simultaneously avoiding "over-sintering" of the surrounding powder and volatilization of the lighter elements (e.g., $\mathrm{Al}$ ). This was done heuristically, by slowly increasing the beam current from $0.1 \mathrm{~mA}$ and manipulating the parameters of beam speed and line order to effectively vary the duration between successive beam passes over a given region (allowing for charge dissipation) while increasing net heat input until sintering occurred.

For the alnico powders this portion of the process development for EBM/PBF AM "workable" parameters were complicated by two key phenomena. First, the observed surface temperature for which sintering was achieved was close to $1100^{\circ} \mathrm{C}$, which is relatively close to the melting (solidus) temperature $\left(\sim 1257^{\circ} \mathrm{C}\right)$. This resulted in a very narrow processing window for preheating: too little energy input and the powder would scatter, too much and the entire layer would over-sinter or begin melting and delaminate causing a spreading failure. Second, based on observations during preheating and melting, it was apparent that the magnetic properties of the powder likely caused a significant deviation in beam focus compared to the calibrated position, although this could not be verified with the available instrumentation. Such effects can have a profound influence on energy and charge transfer into the materials. It is also likely that the magnetic conditions of the powder bed were in constant flux as each new layer was spread and then heated from the as-received condition to above the Curie temperature during preheating, while the electron beam focus and location were also changing. Current predictive models do not account for variation in the magnetic properties of the powder bed during preheating or the potential influence on beam/powder interactions, and further studies will be required to map this process space to enable the stable processing of geometrically complex components. Here we have reported a case for which sintering of the powder bed was achieved without charge induced scattering (run \#5, Table 3; Table 4). Although this is the first reported instance of EBM/PBF of alnico it is anticipated that additional magnetic materials will be developed and trialed within EBM/PBF systems beyond alnico magnets. The magnetic properties of these materials must be carefully tracked, along with potential magnetic field measurements with the AM system, in order to be able to move magnetic material AM technologies forward with appropriate scientific under-pinning. In particular, the Curie and melting temperatures of the magnetic alloys and the pre-heat and EBM temperatures must be correlated to allow optimal AM processing without affecting the AM system nor AM build quality.

Once the stable preheating parameter set was identified, the melting parameters for run \#5 were able to generate a dense sample, $\sim 99.9 \%$ according to optical measurements and $7.17 \pm 0.001 \mathrm{~g} / \mathrm{cc}$ 
as measured by helium pychnometry. The high temperature required for preheating and for the subsequent melting step probably contributed to the observed equiaxed microstructure, as well as to the significant loss of aluminum and copper due to volatilization, significantly altering the composition. This change in composition appears to have led to changes in the expected solidification kinetics and solid-state phase transformations, e.g., the spinodal decomposition, as well as the magnetic properties. Any alteration of the spinodal decomposition phenomena during the MA and the concentration of the diffusing species during the lower temperature draw cycles will ultimately impact the magnetic properties. The loss of both $\mathrm{Al}$ and $\mathrm{Cu}$ was likely a contributor to the observed drop in coercivity as both elements act to separate the Fe-Co rods in the nanostructure; without a high enough concentration of $\mathrm{Al}$ and $\mathrm{Cu}$, the $\mathrm{Fe}-\mathrm{Co}$ rods will no longer be substantially isolated and the coercivity will decrease due to magnetic spin coupling between them $[11,12,34,35]$.

The main objective was to obtain a dense, EBM/PBF build of alnico, thus, unlike the DED samples, EBM/PBF AM processing parameters were not explored. However, minor modifications in the AM processing parameters may have caused the subtle "layered" microstructure (Figure 16) consisting of large and fine grains with a minor $<111>$ and $<101>$ texture. However, this "layered" microstructure was eliminated upon SOQ in which accelerated, uniform grain growth occurred with preliminary indications of a preferred texture. Similar to the DED, the accelerated grain growth observed in $\mathrm{EBM} / \mathrm{PBF}$ samples during the SOQ is likely a product of residual stresses. The higher cooling rate at the interface of the build and build environment in DED vs. EBM/PBF could be exacerbating this effect for the DED samples. Unlike the DED samples, the coercivity was much lower in the EBM/PBF samples in comparison, especially, to the Co-lean DED samples. As mentioned above, the increased grain size of the post-SOQ EBM/PBF samples usually suppresses the formation of $\gamma$-phase and promotes coercivity. Although EBM/PBF and DED as-built samples did not result in a strong $<001>$ texture, minor texturing is evident upon printing, that may be accentuated by SOQ. Thus, texturing in the $<001>$ with an EBM/PBF AM approach may be possible if more analysis and parameter studies are conducted to promote such a texture. Additionally, similar to the DED, there should be more focus in utilizing the residual stress for alignment purposes during the SOQ process. If a $<001>$ texture can be obtained, EBM/PBF could be an attractive processing route for alnico magnets as long as the compositional losses could be mitigated via strategic alloying.

The alnico magnet microstructure is most likely constant during the MA and FHT process since the temperatures are significantly below the SOQ temperatures $\left(830-870{ }^{\circ} \mathrm{C}\right.$ and $650-580^{\circ} \mathrm{C}$, instead of $1210^{\circ} \mathrm{C} / 1215^{\circ} \mathrm{C}$ ) [28]. The highest coercivity values for AM builds were achieved by the DED samples, well above the EBM/PBF samples of similar composition. Again, the loss of $\mathrm{Al}$ and $\mathrm{Cu}$ in the EBM/PBF samples cannot be ignored as a significant factor in this coercivity loss. The highest remanence was achieved by the EBM/PBF samples at lower MA temperatures $\left(830^{\circ} \mathrm{C}\right.$ and $\left.850^{\circ} \mathrm{C}\right)$ and was relatively MA time independent. However, by the same token as coercivity, composition shifts likely contributed to the higher remanence, since remanence can depend on the final chemistry of alnico $[11,13]$. The strong process-property relations of alnico are quite evident in these AM processing results, especially obvious from the wide variation in magnetic properties from different MA times and temperatures of the EBM/PBF samples.

This study encompasses the different magnetic properties of different AM methods and different AM processing parameters, however it's important to compare the resulting AM magnetic properties to the more traditional alnico fabrication methods. DED coercivity values did not differ greatly from those of the full-Co made by either casting or sintering. This is a positive indication that the chemistry is likely not changing significantly during the DED process. The coercivity was higher in the Co-lean DED and higher yet in the cast samples compared to the sintered samples. This value of coercivity is likely due to the lack of MA and draw cycle optimization of the Co-lean DED samples, since coercivity is highly sensitive to this process $[12,20,28]$. In a separate study, it was found that the oxide content of the Co-lean as-sintered powder microstructure was significant, likely leading to more sites for the $\gamma$-phase to form, hence lowering coercivity $[6,25,32]$. To make accurate comparisons between the 
Co-lean sintered and AM samples, oxidation must be prevented during the processing of Co-lean alnico magnets [24]. Remanence was slightly lower in most DED samples of both compositions in comparison to their sintered and cast counterparts with the exception of the B-2 full-Co sample. This may be an indication that a slight texture exists in the DED samples (although not in the desired $<001>$ alignment) that is perhaps developed during the SOQ process. Overall, it is apparent that there is a need for MA and FHT optimization exploration for all DED samples since no samples have approached the theoretical properties that alnico could achieve (calculated in a separate study) [11]. As for the EBM/PBF samples, the coercivity met or was lower than the sintered and cast Co-lean samples, respectively. Again, the loss of $\mathrm{Al}$ and Cu during the EBM/PBF process likely contributed to this finding. Overall, the remanence was about the same or lower than either the cast or sintered samples which may be due to the residual the $<111>$ and $<101>$ texture in the post-SOQ microstructure.

It is anticipated that if greater $<001>$ alignment could be achieved for any alnico AM process, the remanence could be improved and these AM magnets may outperform either cast or sintered alnico magnets. If the composition losses in the EBM/PBF could be addressed and if the $<001>$ texturing could be improved for the DED and EBM/PBF methods of AM, in combination with finding the optimal MA and FHT parameters, the energy product would benefit immensely. These parameters should be optimized appropriately for each composition and AM method to arrive at the ideal spacing, size and magnetic isolation of the Fe-Co rods.

While this study encompasses the variations in magnetic properties of different AM methods and a range of AM processing parameters for alnico magnet alloys, there are demanding applications where it is important to compare the expected mechanical properties to commercial permanent magnets of the alnico, Sm-Co, and Nd-Fe-B type. Since the as-built or annealed mechanical properties of alnico magnets that were produced by both AM methods were not yet tested, one must rely on microstructural observations and analogous test results to predict their general mechanical behavior. Bend strength observations were performed as a function of temperature $\left(-40,25\right.$, and $\left.150{ }^{\circ} \mathrm{C}\right)$ of sintered alnico powder with a similar composition to the AM processed shapes, where sintered alnico of nearly full density exhibited approximately 2 times the bend strength of the baseline RE magnets [36]. The microstructure of the alnico sintered magnets was equiaxed with a grain size $(30-300 \mu \mathrm{m})$ that was very similar to both types of AM processed samples, without any porosity of significant size, but with some fine dispersed oxides from prior particle boundaries. In contrast, microstructural observations of Sm-Co and Nd-Fe-B sintered anisotropic magnets often reveal a much finer grain size $(5-20 \mu \mathrm{m})$. Thus, in spite of several factors that should reduce bend strength, e.g., coarser grain size and oxide particles, alnico still had a much higher bend strength than the ultra-fine grain size of the RE magnets, probably due to the intrinsic brittleness of the crystalline phases in these RE-based materials [37-39]. When compared to alnico magnets made by the more traditional fabrication method of sand casting or more specialized directional solidification, the sintered alnico also had 2 times greater bend strength [36]. The reason for this difference is likely due to typical micro-porosity and minor inclusion content from these large scale casting processes. Thus, it is expected that future mechanical property measurements of similar AM-built samples will be consistent with the sintered alnico properties and should have acceptable mechanical behavior for anticipated applications.

Alnico is a surprising material for AM, not only that it can be built within an electron beam AM system, despite initial concerns about interaction with the magnetic field from the electron beam, but also that it is very buildable in a laser AM system through a wide range of processing parameters. Future work on AM of alnico will include transmission electron microscopy to confirm the Fe-Co rod nanostructure and the influence of chemistry change on the magnetic properties of the EBM/PBF builds. Additional compositions with higher $\mathrm{Al}$ and $\mathrm{Cu}$ content would compensate for volatilization and probably allow higher coercivity values to be achieved with EBM/PBF. Lastly, exploration of the possibility of better grain size control and orientation during processing by adjustment of the AM parameters and post-processing, as well as functionally graded permanent magnet materials should be performed. These accomplishments would greatly expand the use alnico permanent magnet materials 
for increased temperature and mechanically robust uses such as drive motors, electric generators for off-shore wind and other clean energy applications.

\section{Conclusions}

Alnico magnets have been successfully produced using AM processing from pre-alloyed powders of custom compositions using both DED and EBM/PBF methods over a range of processing parameters.

Alnico permanent magnet materials of both Co-lean and full-Co alloys have proven their potential for being processed by DED and are likely suitable for laser melting PBF also. Preliminary observations of DED build samples after SOQ heat treatments in both alloys showed that some uniform grain growth had occurred with some indications of texturing, probably driven by residual stresses in the post-build samples, which might be explored as a useful method of generating an aligned alnico magnet microstructure and improved magnetic properties.

For AM processing by the EBM/PBF method, only the low-Co alloy was used in this study, which focused primarily on achieving acceptable pre-heat and build parameters, without any effort on optimization of the solidification morphology or texture. In fact, the major barrier to generating build samples of adequate size for magnetic treatment and characterization was identification of stable processing space for preheating of the powder bed of this magnetic material, while simultaneously avoiding "over-sintering" of the surrounding powder and volatilization of the lighter elements (e.g., $\mathrm{Al}$ ). The magnetic properties of the powder also likely caused a significant deviation in beam focus compared to the calibrated position, apparently influencing energy and charge transfer into the powders. Additionally, the e-beam focus and location also were changing due to constant variation of the magnetic state of the powder bed as each new layer was spread and then preheated from the as-received condition to above the Curie temperature. This quest for a workable preheat condition finally was satisfied after developing e-beam conditions that entered the narrow preheat process window, between the solidus temperature and the lower bound of the high temperature solid solution, where a useful degree of sintering would occur. Once a stable preheating parameter set was identified, the melting parameters were able to generate a near-dense sample, which was measured at $\sim 99.9 \%$. However, the high temperature required for preheating and the melting step produced an equiaxed microstructure, instead of the desired solidification texture, and resulted in volatilization of $\mathrm{Al}$ and $\mathrm{Cu}$, significantly altering the composition. This change in composition appeared to change solidification and solid-state phase transformation behavior, including the spinodal decomposition that affected the magnetic properties.

In general, the highest coercivity values for alnico AM builds were achieved by the DED samples, well above the EBM/PBF samples of similar composition. Again, the loss of $\mathrm{Al}$ and $\mathrm{Cu}$ in the EBM/PBF samples cannot be ignored as a significant factor in this coercivity loss. The highest remanence was achieved by the EBM/PBF samples at lower MA temperatures and was relatively MA time independent, but composition shifts in $\mathrm{Al}$ and $\mathrm{Cu}$ may have contributed to the higher remanence. The energy product of samples from nearly all the AM methods and alloys was lower but is likely derived from the lack of MA and FHT optimization. If the composition losses in the EBM/PBF could be addressed and if the $<001>$ texturing could be improved for the DED and EBM/PBF methods of AM, in combination with finding the optimal MA and FHT parameters, the energy product would benefit immensely. This is especially obvious from the wide variation in magnetic properties that result from different MA times and temperatures, which control nano-structure development in the EBM/PBF samples to arrive at the ideal spacing, size and magnetic isolation of the Fe-Co rods. Additionally, solidification processing parameters for AM still need to be explored, e.g., potentially a higher thermal gradient within $\mathrm{EBM} / \mathrm{PBF}$, to achieve the ideal microstructure (columnar and textured in the $<001>$ direction) with the highest remanence values. Overall, these alnico AM experiments have proven the buildability of alnico and the resulting magnetic properties authenticate the case for making advanced alnico magnet components by AM for next generation motors and other high temperature, functionally graded or complex engineered part geometry applications. 
Author Contributions: Conceptualization, E.W. and I.A.; data curation, E.W.; formal analysis, E.W., E.R., T.P. and I.A.; funding acquisition, E.W. and I.A.; investigation, E.W., T.P. and T.H.; methodology, T.H., C.L. and C.R.; resources, T.H.; supervision, I.A.; validation, E.R. and T.P.; visualization, T.P.; writing-original draft, E.W.; writing-review and editing, E.W., E.R., T.P., T.H. and I.A.

Funding: This research was funded by the U.S. Department of Energy's Energy Efficiency and Renewable Energy/Vehicle Technologies Office/Electric Drive Technology (DOE-EERE-VTO-EDT) Program and the Office of Technology Transition/Technology Commercialization Fund (OTT-TCF) Program at the Ames Laboratory, which is operated for the U.S. DOE by Iowa State University under contract no. DE-AC02-07CH11358.

Acknowledgments: The authors thank Ryan Ott and Emrah Simsek for their DED experimental work and Dave Byrd and Ross Anderson for performing careful high pressure gas atomization powder production experiments. The authors also are grateful to Matt Kramer, Aaron Kassen, Andriy Palasyuk, Liangfa Hu and Lin Zhou for helpful discussions and guidance. Specific thanks go to Ralph Napolitano for performing thermodynamic calculations to inform the selection of $\mathrm{EBM} / \mathrm{PBF}$ processing parameters.

Conflicts of Interest: The authors declare no conflict of interest.

\section{References}

1. Kramer, M.J.; McCallum, R.W.; Anderson, I.A.; Constantinides, S. Prospects for Non-Rare Earth Permanent Magnets for Traction Motors and Generators. JOM 2012, 64, 752-763. [CrossRef]

2. Skomski, R.; Manchanda, P.; Kumar, P.K.; Balamurugan, B.; Kashyap, A.; Sellmyer, D.J. Predicting the Future of Permanent-Magnet Materials. IEEE Trans. Magn. 2013, 49, 3215-3220. [CrossRef]

3. Kittel, C.; Nesbitt, E.A.; Shockley, W. Theory of magnetic properties and nucleation in alnico V. Phys. Rev. 1950, 77, 839-840. [CrossRef]

4. Nesbitt, E.A.; Williams, H.J. Mechanism of Magnetization in Alnico V. Phys. Rev. 1950, 80, 112-113. [CrossRef]

5. Campbell, R.B.; Julien, C.A. Structure of Alnico v. J. Appl. Phys. 1961, 32, 27-29. [CrossRef]

6. Julien, C.A.; Jones, F.G. Alpha-Sub-Gamma Phase in Alnico 8 Alloys. J. Appl. Phys. 1965, 36, $1173-1174$. [CrossRef]

7. Makino, N.; Kimura, Y. Techniques to Achieve Texture in Permanent Magnet Alloy Systems. J. Appl. Phys. 1965, 36, 1185-1190. [CrossRef]

8. Cronk, E.R. Recent Developments in High-Energy Alnico Alloys. J. Appl. Phys. 1966, 37, 1097-1100. [CrossRef]

9. Sergeyev, V.; Bulygina, T. Magnetic properties of alnico 5 and alnico 8 phases at the sequential stages of heat treatment in a field. IEEE Trans. Magn. 1970, 6, 194-198. [CrossRef]

10. McCurrie, R.A. Ferromagnetic Materials: Structure and Properties; Academic Press: London, UK; San Diego, CA, USA, 1994.

11. Zhou, L.; Miller, M.; Lu, P.; Ke, L.; Skomski, R.; Dillon, H.; Xing, Q.; Palasyuk, A.; McCartney, M.; Smith, D.; et al. Architecture and magnetism of alnico. Acta Mater. 2014, 74, 224-233. [CrossRef]

12. Zhou, L.; Tang, W.; Guo, W.; Poplawsky, J.D.; Anderson, I.E.; Kramer, M. Spinodal Decomposition in an Alnico Alloy. Microsc. Microanal. 2016, 22, 670-671. [CrossRef]

13. Palasyuk, A.; Blomberg, E.; Prozorov, R.; Yue, L.; Kramer, M.J.; McCallum, R.W.; Anderson, I.E.; Constantinides, S. Advances in Characterization of Non-Rare-Earth Permanent Magnets: Exploring Commercial Alnico Grades 5-7 and 9. JOM 2013, 65, 862-869. [CrossRef]

14. Zhou, L.; White, E.; Ke, L.; Cullen, D.A.; Lu, P.; Constantinides, S.; McCallum, R.W.; Anderson, I.E.; Kramer, M.J. Microstructure and coercivity in alnico 9. J. Magn. Magn. Mater. 2019, 471, 142-147. [CrossRef]

15. Sames, W.J.; List, F.A.; Pannala, S.; Dehoff, R.R.; Babu, S.S. The metallurgy and processing science of metal additive manufacturing. Int. Mater. Rev. 2016, 61, 315-360. [CrossRef]

16. White, E.M.H.; Kassen, A.G.; Simsek, E.; Tang, W.; Ott, R.T.; Anderson, I.E. Net Shape Processing of Alnico Magnets by Additive Manufacturing. IEEE Trans. Magn. 2017, 53, 1-6. [CrossRef]

17. Li, L.; Tirado, A.; Nlebedim, I.C.; Rios, O.; Post, B.; Kunc, V.; Lowden, R.R.; Lara-Curzio, E.; Fredette, R.; Ormerod, J.; et al. Big Area Additive Manufacturing of High Performance Bonded NdFeB Magnets. Sci. Rep. 2016, 6, 36212. [CrossRef] [PubMed]

18. Paranthaman, M.P.; Shafer, C.S.; Elliott, A.M.; Siddel, D.H.; McGuire, M.A.; Springfield, R.M.; Martin, J.; Fredette, R.; Ormerod, J.; Paranthaman, M. Binder Jetting: A Novel NdFeB Bonded Magnet Fabrication Process. JOM 2016, 68, 1978-1982. [CrossRef] 
19. Dehoff, R.R.; Kirka, M.M.; Sames, W.J.; Bilheux, H.; Tremsin, A.S.; Lowe, L.E.; Babu, S.S. Site specific control of crystallographic grain orientation through electron beam additive manufacturing. Mater. Sci. Technol. 2015, 31, 931-938. [CrossRef]

20. Tang, W.; Zhou, L.; Kassen, A.G.; Palasyuk, A.; White, E.M.; Dennis, K.W.; Kramer, M.J.; McCallum, R.W.; Anderson, I.E. New Alnico Magnets Fabricated From Pre-Alloyed Gas-Atomized Powder Through Diverse Consolidation Techniques. IEEE Trans. Magn. 2015, 51, 1-3. [CrossRef]

21. Anderson, I.E.; Kassen, A.G.; White, E.M.H.; Zhou, L.; Tang, W.; Palasyuk, A.; Dennis, K.W.; McCallum, R.W.; Kramer, M.J. Novel pre-alloyed powder processing of modified alnico 8: Correlation of microstructure and magnetic properties. J. Appl. Phys. 2015, 117, 17D138. [CrossRef]

22. Behrmann, E.; Farchy, J.; Dodge, S. Hype Meets Reality as Electric Car Dreams Run Into Metal Crunch. Bloomberg. 2018. Available online: https://www.bloomberg.com/graphics/2018-cobalt-batteries/ (accessed on 17 September 2019).

23. McKerracher, C.; Izadi-Najafabadi, A.; Soulopoulos, N.; Doherty, D.; Frith, J.; Albanese, N.; Grant, A.; Berryman, I.; Mi, S.; Asghar, A.; et al. Electric Vehicle Outlook 2019. Bloomberg. 2019. Available online: https://about.bnef.com/electric-vehicle-outlook/ (accessed on 17 September 2019).

24. Rinko, E.; Anderson, I.; Kassen, A.; White, E.; Tang, W.; Zhou, L.; Pries, J.; Kramer, M. Investigation of Powder Processing, Heat Treating, and Texturing to Improve Gas-Atomized Alnico Magnets for Use in Electric Drive Motors. In Proceedings of the International Conference on Powder Metallurgy \& Particulate Materials, Phoenix, AR, USA, 23-26 June 2019; pp. 500-515.

25. Rinko, E. Exploring Powder Processing of Cobalt-Lean Alnico Alloy as a Preferred Approach to Produce Full-Scale High-Performance Alnico Magnets with Near-Final Shape. In Advances in Powder Metallurgy $\mathcal{E}$ Particulate Materials; Bose, A., Davis, S., Eds.; Metal Powder Industries Federation: Princeton, NJ, USA, 2018; pp. 385-397.

26. Kassen, A.G.; Gregory, A. Exploration of Alnico Permanent Magnet Microstructure and Processing for Near Final Shape Magnets with Solid-State Grain Alignment for Improved properties. Ph.D. Thesis, lowa State University, Ames, IA, USA, 2018.

27. Dillion, H. Effects of Heat Treatment and Processing Modification on Microstructure in Alnico 8H Permanent Magnet Alloys for High Temperature Applications. Master's Thesis, Iowa State University, Ames, IA, USA, 2014.

28. Zhou, L.; Tang, W.; Ke, L.; Guo, W.; Poplawsky, J.D.; Anderson, I.E.; Kramer, M.J. Microstructural and magnetic property evolution with different heat-treatment conditions in an alnico alloy. Acta Mater. 2017, 133, 73-80. [CrossRef]

29. Sigl, M.; Lutzmann, S.; Zaeh, M.F.; Management, I.; Muenchen, T.U. Transient Physical Effects in Electron Beam Sintering; Institute for Machine Tools and Industrial Management: Munich, Germany, 2006; pp. 464-477.

30. Eschey, C.; Lutzmann, S.; Zaeh, M.F. Examination of the powder spreading effect in Electron Beam Melting (EBM). In Proceedings of the Annual International Solid Freeform Fabrication Symposium, Austin, TX, USA, 3-5 August 2009; pp. 308-319.

31. Cordero, Z.C.; Meyer, H.M.; Nandwana, P.; Dehoff, R.R. Powder bed charging during electron-beam additive manufacturing. Acta Mater. 2017, 124, 437-445. [CrossRef]

32. Szymura, S.; Wyslocki, B.; Skubela, L. Contribution to the study of Alpha-Sub-Gamma Phase in alnico 8 alloys. J. Magn. Magn. Mater. 1982, 27, 175-181. [CrossRef]

33. Anderson, I.E.; Kassen, A.G.; White, E.M.H.; Palasyuk, A.; Zhou, L.; Tang, W.; Kramer, M.J. Development of controlled solid-state alignment for alnico permanent magnets in near-final shape. AIP Adv. 2017, 7, 056209. [CrossRef]

34. Ke, L.; Skomski, R.; Hoffmann, T.D.; Zhou, L.; Tang, W.; Johnson, D.D.; Kramer, M.J.; Anderson, I.E.; Wang, C.Z. Simulation of alnico coercivity. Appl. Phys. Lett. 2017, 111, 022403. [CrossRef]

35. Zhou, L.; Miller, M.K.; Dillon, H.; Palasyuk, A.; Constantinides, S.; McCallum, R.W.; Anderson, I.E.; Kramer, M.J. Role of the Applied Magnetic Field on the Microstructural Evolution in Alnico 8 Alloys. Met. Mater. Trans. E 2014, 1, 27-35. [CrossRef]

36. Hu, L.; Anderson, I.; Kassen, A.; White, E.; Tang, W.; Zhou, L.; Kramer, M.; DeVoto, D.; Major, J.; Bennion, K.; et al. High-Performance Alnico Magnets with Near-Final Shape. In Proceedings of the 62nd Annual Conference on Magnetism and Magnetic Materials, Pittsburgh, PA, USA, 6 November 2017.

37. Curran, R.E. Intercrystalline Fracture in Alnico 5. J. Appl. Phys. 1966, 37, 1106-1107. [CrossRef] 
38. Horton, J.; Wright, J.; Herchenroeder, J. Fracture toughness of commercial magnets. IEEE Trans. Magn. 1996, 32, 4374-4376. [CrossRef]

39. Singh, R.; Kamat, S.; Mathur, R. Fracture toughness studies in sintered SmCo5 magnets. J. Magn. Magn. Mater. 2015, 379, 300-304. [CrossRef]

(C) 2019 by the authors. Licensee MDPI, Basel, Switzerland. This article is an open access article distributed under the terms and conditions of the Creative Commons Attribution (CC BY) license (http://creativecommons.org/licenses/by/4.0/). 